\title{
Integrin av $\beta 3$ and CD44 pathways in metastatic prostate cancer cells support osteoclastogenesis via a Runx2/Smad 5/receptor activator of NF-KB ligand signaling axis
}

\author{
Aditi Gupta', Wei Cao ${ }^{2}$ and Meenakshi A Chellaiah ${ }^{{ }^{*}}$
}

\begin{abstract}
Background: Bone loss and pathological fractures are common skeletal complications associated with androgen deprivation therapy and bone metastases in prostate cancer patients. We have previously demonstrated that prostate cancer cells secrete receptor activator of NF-kB ligand (RANKL), a protein essential for osteoclast differentiation and activation. However, the mechanism(s) by which RANKL is produced remains to be determined. The objective of this study is to gain insight into the molecular mechanisms controlling RANKL expression in metastatic prostate cancer cells.

Results: We show here that phosphorylation of Smad 5 by integrin av 33 and RUNX2 by CD44 signaling, respectively, regulates RANKL expression in human-derived PC3 prostate cancer cells isolated from bone metastasis. We found that RUNX2 intranuclear targeting is mediated by phosphorylation of Smad 5. Indeed, Smad5 knock-down via RNA interference and inhibition of Smad 5 phosphorylation by an av inhibitor reduced RUNX2 nuclear localization and RANKL expression. Similarly, knockdown of CD44 or RUNX2 attenuated the expression of RANKL. As a result, conditioned media from these cells failed to support osteoclast differentiation in vitro. Immunohistochemistry analysis of tissue microarray sections containing primary prostatic tumor (grade2-4) detected predominant localization of RUNX2 and phosphorylated Smad 5 in the nuclei. Immunoblotting analyses of nuclear lysates from prostate tumor tissue corroborate these observations.
\end{abstract}

Conclusions: Collectively, we show that CD44 signaling regulates phosphorylation of RUNX2. Localization of RUNX2 in the nucleus requires phosphorylation of Smad-5 by integrin av $\beta 3$ signaling. Our results suggest possible integration of two different pathways in the expression of RANKL. These observations imply a novel mechanistic insight into the role of these proteins in bone loss associated with bone metastases in patients with prostate cancer.

Keywords: PC3 cells, RANKL, RUNX2, Smad 5, CD44, Integrin avß3, Osteoclasts, PKC

\section{Introduction}

Prostate cancer is the most prevalent non-skin cancer to affect men and it is the second leading cause of cancerrelated deaths in Western males [1,2]. The majority of the patients with advanced prostate cancer will eventually develop bone metastases [3]. Prostate cancer cells that metastasize to bone have the capacity to produce

\footnotetext{
*Correspondence: mchellaiah@umaryland.edu

'Department of Oncology and Diagnostic Sciences, Dental School, University of Maryland, Baltimore, MD 21201, USA

Full list of author information is available at the end of the article
}

osteolytic lesions which are due to activation of osteoclasts [4]. Likewise, bone loss is increasingly recognized as a common occurrence in men diagnosed with prostate cancer receiving androgen deprivation therapy (ADT). The receptor activator of nuclear factor kB ligand (RANKL) is an essential cytokine required for the formation and activation of osteoclasts [5-7]. The involvement of RANKL in the progression of prostate tumor growth within bone and the subsequent bone loss has been recently established in animal models of cancer metastasis [8-13].

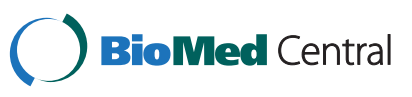


Runx2, a transcription factor that plays a key regulatory role in osteoblast differentiation, is also highly expressed in bone metastatic breast and prostate cancer cells [14-16]. RUNX2 increases the oncogenic potential through regulation of genes (e.g. MMP2, MMP9, and MMP13) involved in metastasis and invasion of prostate and breast cancer cells [17-19]. RUNX2 expression in cancer cells facilitates the interaction between tumor cells and the bone microenvironment that lead to osteolytic disease $[15,20]$. For instance, in vivo blockade of the Runx2-Indian hedgehog pathway in MDA-MB-231 cells by targeting Runx 2 with short hairpin RNA prevented osteolytic disease [21]. Furthermore, the presence of putative binding sites for RUNX2 in the promoter region of RANKL [22] and a striking decrease in the number of osteoclasts in RUNX2- (Cbfa1-) deficient mice [22] suggest that RUNX2 is potentially involved in RANKL expression.

Smads, a family of proteins involved in the translocation of signals from receptors to the nucleus have been shown to physically interact with RUNX2 [23]. Interaction between these proteins results in the formation of transcriptionally active complexes which hold the potential to regulate various developmental and biological processes [24,25]. In fact, cooperation between Smads and RUNX2 induces osteoblast specific gene expression in mesenchymal stem cells to promote osteoblast differentiation [24,26,27]. The role of RUNX2 and Smads has been extensively studied in a variety of cell systems. However, the combined roles of these proteins and their signaling mechanisms on RANKL expression in bone metastatic prostate cancer cells have been largely unexplored.

Integrin $\alpha v \beta 3$ and CD44 signaling have been shown to increase the metastatic potential of cancer cells [28-30]. Integrin $\alpha v \beta 3$ expression in tumor cells accelerates the development of osteolytic lesions [31]. Integrin $\alpha v \beta 3$ signaling has been implicated in the expression of RANKL and osteoclastogenesis by breast cancer in the bone microenvironment [32]. CD44 signaling increases the metastatic potential of prostate cancer cells [33,34]. Altered levels of CD44 have been seen in many epithelial neoplasms and expression of CD44 has been shown to carry prognostic implications [35,36]. RUNX2 expression is regulated by CD44 signaling [37]. A neutralizing antibody to CD44s significantly decreased the expression of Runx2 mRNA in hypertrophic chondrocytes [37]. CD44 signaling is a determinant of inflammatory bone loss through expression of RANKL [38,39]. PC3 and LNCaP cell lines have been used by many researchers to document the role of CD44 in the metastatic process [40-43]. We have previously demonstrated that osteopontin regulates the expression and secretion of RANKL in PC3 cells [28]. However, the molecular mechanisms underlying the expression of RANKL are not fully understood. The role of multiple receptor signaling pathways (for e.g. CD44 and integrin $\alpha v \beta 3$ ) converge on the transcriptional factor(s) to regulate RANKL expression needs further elucidation.

Therefore, our aim is to further elucidate the mechanisms by which RANKL expression is regulated by testing the hypothesis that integrin $\alpha v \beta 3$ and CD44 signaling plays a key role in mediating the expression of RANKL. Understanding the molecular mechanisms underlying RANKL expression may provide a valuable insight into the process of osteoclast differentiation and the resultant bone resorptive activities within the skeletal microenvironment. In the present study, the cooperative role of RUNX2 and Smad5 in the expression of RANKL was studied in PC3 cells. Here, we provide compelling evidence that a) CD44 signaling regulates the phosphorylation of RUNX2; b) CD44 knockdown reduced RUNX2 phosphorylation, but not Smad 5 phosphorylation; c) knockdown of Smad 5 levels or suppression of phosphorylation of Smad 5 by an inhibitor to integrin $\alpha v$ reduced nuclear localization of RUNX2, and d) inhibition of phosphorylation of either RUNX2 or Smad 5 reduces the expression of RANKL and osteoclast differentiation.

\section{Results}

We have primarily used PC3 cells derived from bony metastasis for various analyses. We have also used prostate cancer cells derived from brain (DU145) and lymph node (LNCaP) metastases for comparative analyses. Normal prostatic epithelial (HPR1) and benign prostatic hyperplasic $(\mathrm{BPH})$ cells were used as controls.

\section{RUNX2 expression is markedly increased in bone metastatic prostate cancer cells}

We initially examined the levels of RUNX2 expression in PC3 and control (HPR1 and BPH) cell lines (Figure 1A). RUNX2 expression was considerably higher at mRNA (Figure 1A, lane 1) and protein (B, lane 1) levels as compared with other control cell lines tested (A and B; lanes 2 and 3).

\section{RUNX2 ablation reduces RANKL expression}

RUNX2 is linked to MMP9 and RANKL expression $[44,45]$. First, we attempted to determine the efficient dose of SiRNA to RUNX2 to knockdown RANKL. The knockdown of Runx2 by RNA interference decreases MMP9 expression [44]. Therefore, we have assessed the effects of different doses $(10,25,50 \mathrm{nM})$ of RUNX2 SiRNA nucleotide on the expression of MMP9 and MMP2 at mRNA and protein levels (Additional file 1: Figure S1). RT-PCR analysis demonstrated dose-dependent decrease in the expression of MMP9 at mRNA level and not MMP2. The decrease was maximal at 50nM (>90\%; Additional file 1: Figure S1A). A significant decrease in the expression of MMP9 and not MMP2 protein was observed with 50nM 


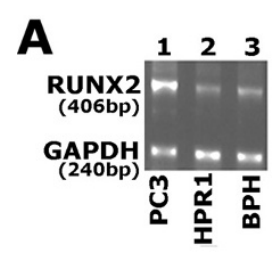

C
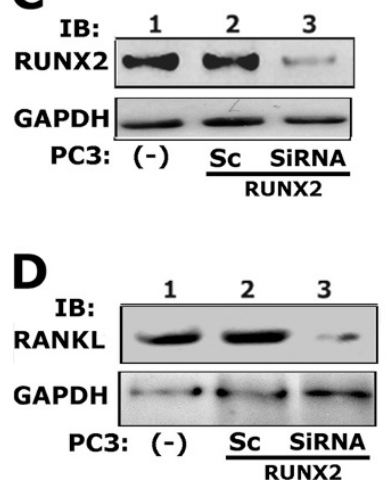
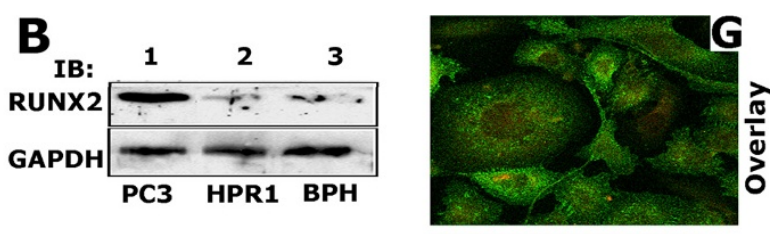

E
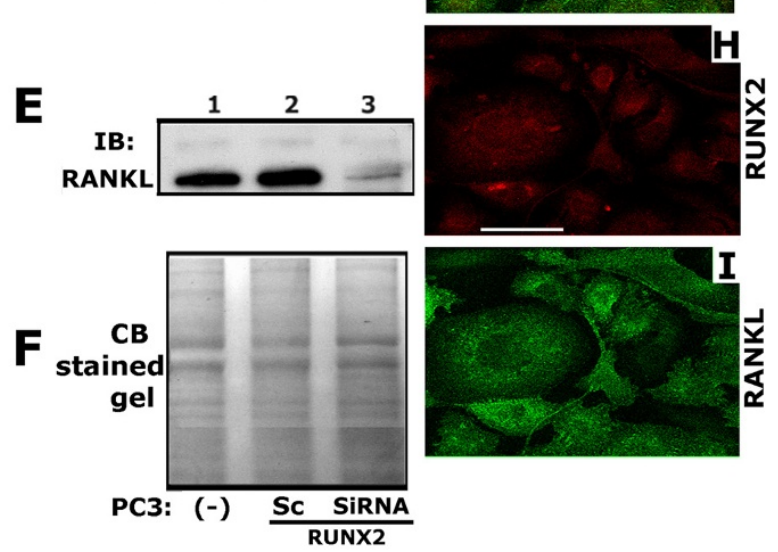

Figure 1 Analysis of expression of RUNX2 and RANKL in PC3 cells. A and B. RT-PCR and immunoblotting analysis of expression of RUNX2 in PC3 (lanes 1), HPR1 (lane 2) and BPH (lane 3) cells is shown. C-E: The effects of SiRNA to RUNX2 on RUNX2 (C) and RANKL (D) protein levels in total cellular lysates ( $C$ and $D$ ) and conditioned medium (E). Immunoblotting analysis in conditioned medium represents the secreted levels of RANKL. Untransfected (-) or scrambled SiRNA (Sc) transfected PC3 cells were used as controls (B-E). GAPDH was used as a loading control for RT-PCR (A) and Western blot (B -D) analyses. The loading control for the conditioned medium is shown by the use of Coomassie blue staining of the blot ( $F$ ). G - I: Immunostaining and confocal microscopy analysis of distribution of RUNX2 (red; H) and RANKL (green; I) in PC3 cells. Distribution of both RANKL (red) and RUNX2 (green) are shown in panel G. Results shown are representative of three independent experiments. Scale bar: 50 um.

SiRNA to RUNX2 (Additional file 1: Figure S1D and E). Therefore, in further experiments, PC3 cells were transfected with 50nM SiRNA nucleotides to RUNX2. Immunoblotting analysis shows the silencing effect $>80 \%$ at 50nM SiRNA on RUNX2 protein level (Figure 1C, lane 3).

Subsequently, we determined the effects of RUNX2 knockdown on the expression of RANKL in PC3 cells treated with 50nM SiRNA. RUNX2 ablation reduces total cellular and secreted (Figure 1D and E, lane 3) RANKL to a significant level (>85\%). Secreted RANKL was determined in the conditioned medium ( $\mathrm{E}$ and $\mathrm{F}$ ). Untransfected ((-); C-F, lane 1) and ScSiRNA (50nM; lane 2 in C-F) transfected PC3 cells were used as controls.

\section{Differential intracellular localization of RANKL and RUNX2} in PC3 cells

We examined the cellular distribution of RANKL and RUNX2 by immunostaining and confocal analyses in PC3 cells (Figure 1G-I). Diffuse and punctate distribution of RANKL (green) and RUNX2 (red) was observed. RUNX2 distribution was observed in the perinuclear and nuclear region. Lateral confocal sectioning and $\mathrm{XZ}$ scanning of PC3 cells displayed distribution of RANKL throughout cytoplasm and membrane (data not shown). Colocalization of RANKL and RUNX2 was negligible. Differential subcellular localization of these proteins may be important for their function.
ChIP analysis of Runx2-binding sites in the RANKL promoter

Two sets of primers specific for RUNX2 binding sites on RANKL promoter were used to detect the DNA fragment (153 bp; Figure 2A, lanes 2 and 4) positioned between nucleotide -143 and -300 in human RANKL promoter [46]. This fragment encompasses the RUNX2 binding site located between -228 to -234 nucleotides. RT-PCR analysis demonstrated the expected product of $153 \mathrm{bp}$ DNA fragment which suggests direct binding of RUNX2 to the RANKL promoter (Figure 2A, lanes 2 and 4).

\section{Ablation of RUNX2 reduces osteoclast differentiation}

To analyze whether RUNX2 knockdown in PC3 cells would modulate osteoclast differentiation, conditioned media (CM; 50-100 $\mu \mathrm{g}$ protein) from PC3 cells untreated (Figure 2B) or treated with scrambled (C) and SiRNA (D) to RUNX2 were incubated with mouse bone marrow cells in the presence of mCSF1 to induce osteoclast differentiation in vitro. As shown in Figure 2, CM from PC3 cells untransfected (B) or transfected with scrambled SiRNA to RUNX2 induces differentiation of bone marrow cells to mature osteoclasts. Conversely, osteoclast differentiation was prevented by $\mathrm{CM}$ from PC3 cells knockdown of RUNX2 (D) suggesting that RUNX2 regulates RANKL expression, and that secretion of RANKL by metastatic 


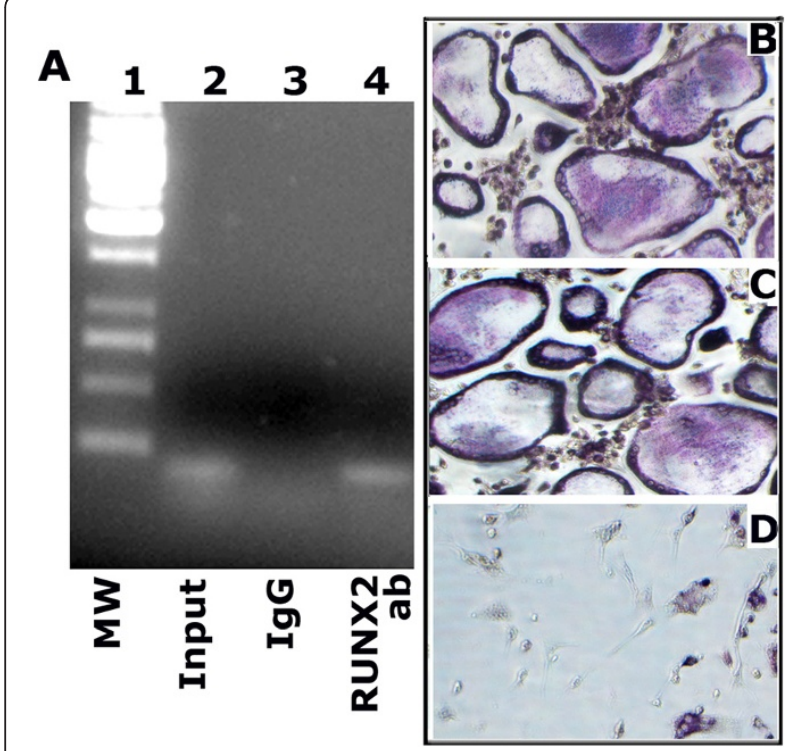

Figure 2 Analysis of binding of RUNX2 with RANKL promoter and the effect of RUNX2 knockdown on osteoclast differentiation. A. Chromatin immunoprecipitation (ChIP) assay. ChIP assay was used to determine the RUNX2 binding sites in RANKL promoter. Immunoprecipitates were made with an antibody (rabbit) to RUNX2 (lane 4) or rabbit IgG (lane 3) using lysates made from PC3 cells. DNA from the input (lane 2) and immunoprecipitates (lanes 3 and 4) was analyzed by RT-PCR using primers specific for RUNX2 binding sites on RANKL promoter. As expected, a product size 153 bp was observed in the RT-PCR analysis. The experiment was repeated twice and obtained similar results. B-D: The conditioned media (CM) from PC3 cells untreated (B) or treated with scrambled (C) and SiRNA (D) to RUNX2 were used for osteoclast differentiation in vitro. TRAP-positive osteoclasts are stained in dark purple. Cells were observed under an inverted phase contrast microscope and images were captured (X 200). The results shown are representative of three experiments.

prostate cancer cells in the bone microenvironment may support osteoclastogenesis and osteolysis.

\section{CD44 knockdown reduces RANKL expression and osteoclast differentiation}

Our previous observation demonstrated an underlying correlation between osteopontin/CD44 signaling and RANKL expression [28]. CD44 increases RANKL expression in bone marrow stromal cells (BMSCs). BMSCs isolated from CD44 knockout mice express less RANKL [47]. Therefore, we sought to determine in PC3 cells, the possible regulatory mechanisms involved in the activation of RUNX2 and the role of CD44 signaling in this process.

\section{CD44 is highly expressed in PC3 cells}

At first, we evaluated the expression levels of CD44 in control cells (HPR1 and BPH) and prostate cancer cells derived from bone (PC3), lymph node (LNCaP) and brain (DU145) metastases (Figure 3A). Expression of CD44 was observed in the following order in the cell lines tested:
PC3 $>$ DU145 $>$ BPH $=$ HPR1 (Figure 3A). The blot shown in Figure $3 \mathrm{~A}$ was exposed for $>5 \mathrm{~min}$ in order to observe the expression levels of CD44 in LNCaP, BPH and HPR-1 cells. Expression of CD44 was very negligible in $\mathrm{BPH}$ and HPR-1 cells. As shown by others, CD44 was not observed in LNCaP cells (Figure 3A) [40,48,49].

\section{Generation of stable CD44 knockdown PC3 cells}

In order to determine the role of CD44 in the expression of RANKL, we have generated PC3 cells knockdown of CD44. Four constructs were made to knockdown CD44 as described in the Methods section. A significant decrease in the expression levels of CD44 was observed in PC3 cells transfected with silencing CD44 ShRNA constructs corresponding to nucleotide sequences $492 \mathrm{bp}$ and 801 bp (Figure 3C). We have generated about 15-20 individual clones and tested for the expression of CD44. The expression levels of standard CD44 in the clonal isolates of 801 (lanes 1-3) and 492 (lanes 4 and 5) ShRNA constructs are shown (Figure $3 \mathrm{C}$ ). Among the individual clones tested, one clonal isolate which demonstrated maximum knockdown of CD44 from 801 and 492 group (Figure 3C, lanes 1 and 5) was propagated for further studies shown below. Additionally, immunoblot analyses show that these cells are negative for CD44 variant isoforms (data not shown). Non-silencing scrambled ShRNA (Sc) construct and vector DNA (V) transfected cells were used as controls.

\section{RANKL expression and osteoclast differentiation is reduced in PC3 cells knockdown of CD44}

We subsequently evaluated the total cellular (Figure 4A) and secreted (Figure 4C) levels of RANKL in CD44 knockdown clones and control cells. Secreted levels of RANKL in CM (Figure 4C, lane 3) and the effect of CM on osteoclast differentiation (Figure 4G) were shown with studies carried with a clonal isolate derived from the 801 bp construct. A significant decrease in the cellular (Figure 4A, lanes 2 and 3) and secreted levels (Figure 4C, lanes 3) of RANKL was observed in CD44 knockdown cells (PC3/Sh (801)) as compared with control cells (A, lanes 1 and 4; C, lanes 1 and 2).

CM from PC3/ShCD44 (801) cells failed to support differentiation of mouse bone marrow cells into multinucleated osteoclasts (Figure 4G). Multinucleated giant osteoclasts were observed in bone marrow cultures added with CM media from control PC3 cells (Figure 4E and F). Overall, these results implicate CD44 signaling as an important mediator of RANKL expression.

\section{CD44 signaling regulates RUNX2 expression}

CD44-mediated signaling appears to have a role in the expression of RUNX2 because a neutralizing antibody to CD44 attenuated RUNX2 expression in chondrocytes 


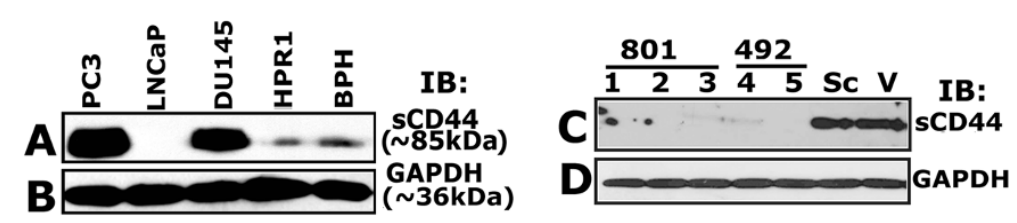

Figure $\mathbf{3}$ Characterization of stable CD44 knockdown cell lines. A. Western blot analysis: Equal amount of protein lysates (50 $\mu \mathrm{g})$ made from indicated cell lines were immunoblotted with a CD44 antibody to detect total cellular levels of CD44 protein. C. Immunoblotting analysis of the total cellular levels of CD44 in the stable clonal isolates derived from PC3 cells transfected with CD44 ShRNA constructs (801 and 492; lanes 1-5) is shown. PC3 cells transfected with vector DNA ( $)$ and scrambled ShRNA construct (Sc) were used as controls. B and D: Equal loading of protein was verified with the GAPDH level in each lane. The experiment was carried out three times with similar results.

[39]. Therefore, we examined the functional relationship between CD44 receptor and RUNX2 expression in indicated PC3 cell lines by real-time PCR (Figure 5A) and Western blot (Figure 5B) analyses. Knockdown of CD44 in PC3 cells reduces the expression of RUNX2 at mRNA (Figure 5A; sh801) and protein levels (B, Sh492 and 801) as compared to indicated control cells.

Previous studies have shown that phosphorylation of RUNX2 occurred mostly on the serine residues with a small amount at threonine and tyrosine residues [19,50]. Therefore, we determined the serine phosphorylation status of RUNX2 (Figure 5E) in PC3 cells. RUNX2 immunoprecipitates from total cellular $(\mathrm{T})$ and nuclear $(\mathrm{N})$ lysates were used for immunoblotting with an antibody to RUNX2 (D) and phospho-Serine (p-Serine; E). Phosphorylation of RUNX2 corresponds with the protein level present in the whole cell and nuclear lysates.
Reduced phosphorylation corresponds with the low levels of RUNX2 in whole cell lysates (D and E, lane 1) and the opposite is true for the nuclear lysates (lane 2 in $\mathrm{D}$ and $\mathrm{E})$. This result is in agreement with the nuclear localization of RUNX2 in immunostaining analysis (Figure 1G).

\section{p-Smad 5 localizes in the nuclear region}

Several lines of evidence suggest that RUNX2 functions synergistically with a family of Smad proteins to induce osteogenesis and modulate tumor growth and metastasis [51].Therefore, we proceeded to determine whether Smad protein(s) have any synergistic role with RUNX2. First, we analyzed the expression and phosphorylation levels of Smad 2, 3, 5 and 6 in total PC-3 cellular lysates. Our analyses indeed have shown the presence of Smad 2, 3 and Smad 5 proteins and not Smad 6 in PC3 cells.

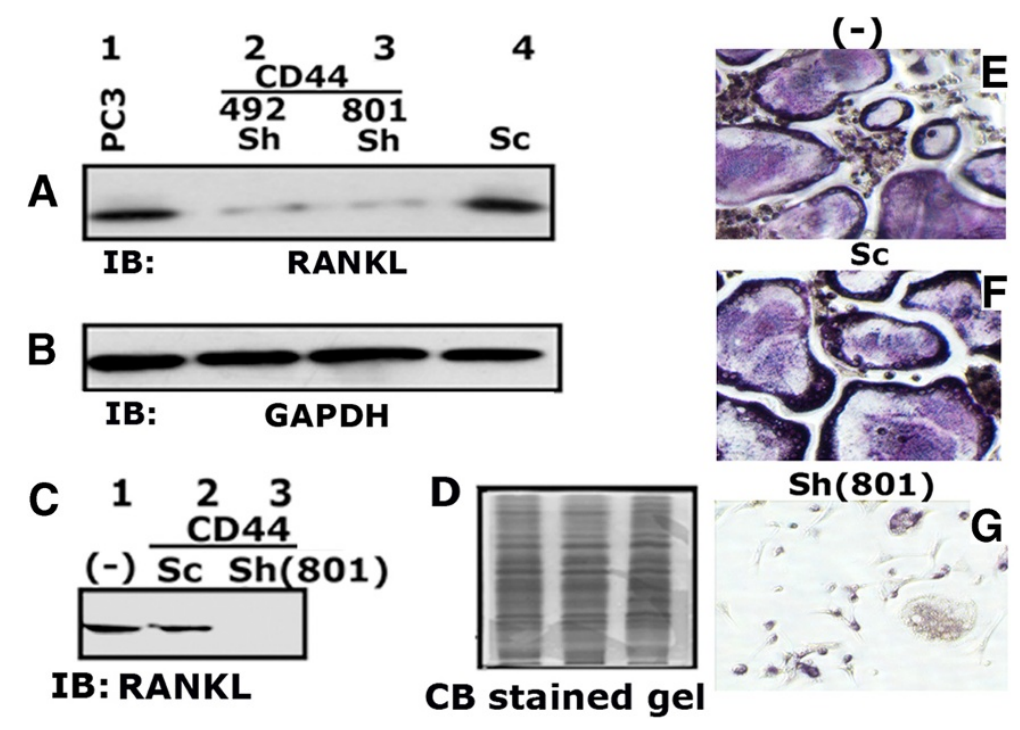

Figure 4 Analysis of RANKL expression level in PC3 cells knockdown of CD44. A and C. Equal amount of total cellular lysates (50 $\mu \mathrm{g}$ protein; A) and conditioned media (CM-20 $\mu \mathrm{g}$ protein; C) were immunoblotted with a RANKL antibody to detect RANKL protein. CM was used to detect the secreted RANKL protein. B and D. The blot in A was stripped and reprobed with a GAPDH antibody. Equal level of GAPDH protein was observed (B). The loading control for the CM was shown by the use of Coomassie blue staining of a gel ran in parallel (D). E-G. The effect of CM on osteoclast differentiation in vitro is shown. TRAP-positive osteoclasts are stained in dark purple. Images were captured (X 200) with an inverted phase contrast microscope. The results shown are representative of three independent experiments. 

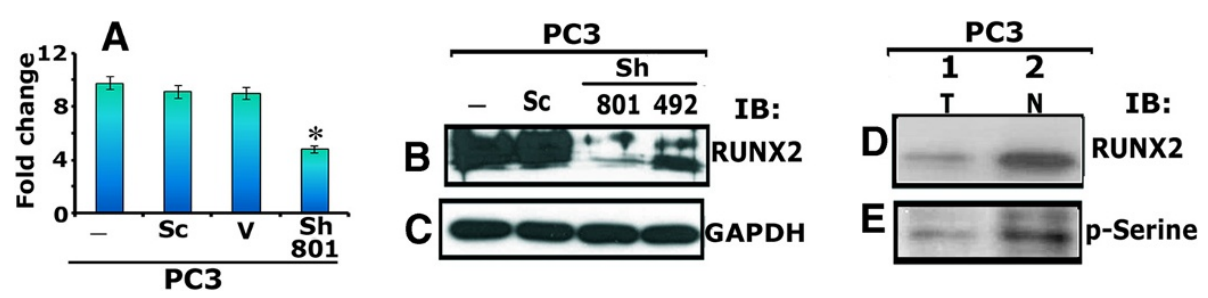

Figure 5 Effects of CD44 knockdown on RUNX2 expression (mRNA and protein) and distribution in PC3 cells. A. The expression levels of RUNX2 mRNA was determined by real-time PCR analysis and normalized relative to GAPDH expression. Bar represents the mean \pm SEM of three different experiments. ${ }^{*} p<0.01$ vs. untransfected (-) and transfected PC3 cells with scrambled ShRNA construct (Sc) and vector DNA (V). B and $\mathbf{C}$. Equal amount of lysates $(20 \mathrm{\mu g}$ protein) made from PC3 cells untransfected (-) and transfected with scramble (Sc) and ShRNA CD44 constructs (492 and 801) were used for immunoblotting analysis with an antibody to RUNX2. Immunoblotting with an antibody to GAPDH (C) was used as a loading control. D and E. PC3 cells were analyzed for the phosphorylation of RUNX2 in total cellular (T) and nuclear (N) lysates by immunoblotting of RUNX2 immunoprecipitates with antibodies to RUNX2 (D) and phospho-serine (E; p-Serine). The results shown are representative of three independent experiments.

However, we found that the phosphorylation status of Smad 5 was significantly higher than in Smad 2 and 3 (see Additional file 2: Figure S2). Therefore, we decided to focus our attention on the role of Smad 5 in RUNX2 function.

We first investigated the nuclear $(\mathrm{N}, 100 \mu \mathrm{g})$, cytoplasmic $(\mathrm{C}, 100 \mu \mathrm{g})$ and total cellular $(\mathrm{T}, 200 \mu \mathrm{g})$ levels of Smad 5 (Figure 6 A) and phospho-Smad 5 (p-Smad 5; B) by immunoblotting analyses. Smad 5 was observed predominantly in total cellular (T) and cytosolic (C) lysates (Figure 6A, lanes 2 and 3). However, a significantly lower level of p-Smad 5 was observed in the cytosolic protein (Figure 6B, lane 2). In contrast, equal levels of phosphorylation of Smad 5 was detected in total cellular and nuclear (N) lysates (Figure 6B, lanes 1 and 3) although significantly lower level of Smad 5 was present in the nuclear lysates (A, lane 1$)$. It is possible that the p-Smad 5 recognized in the total cellular lysate
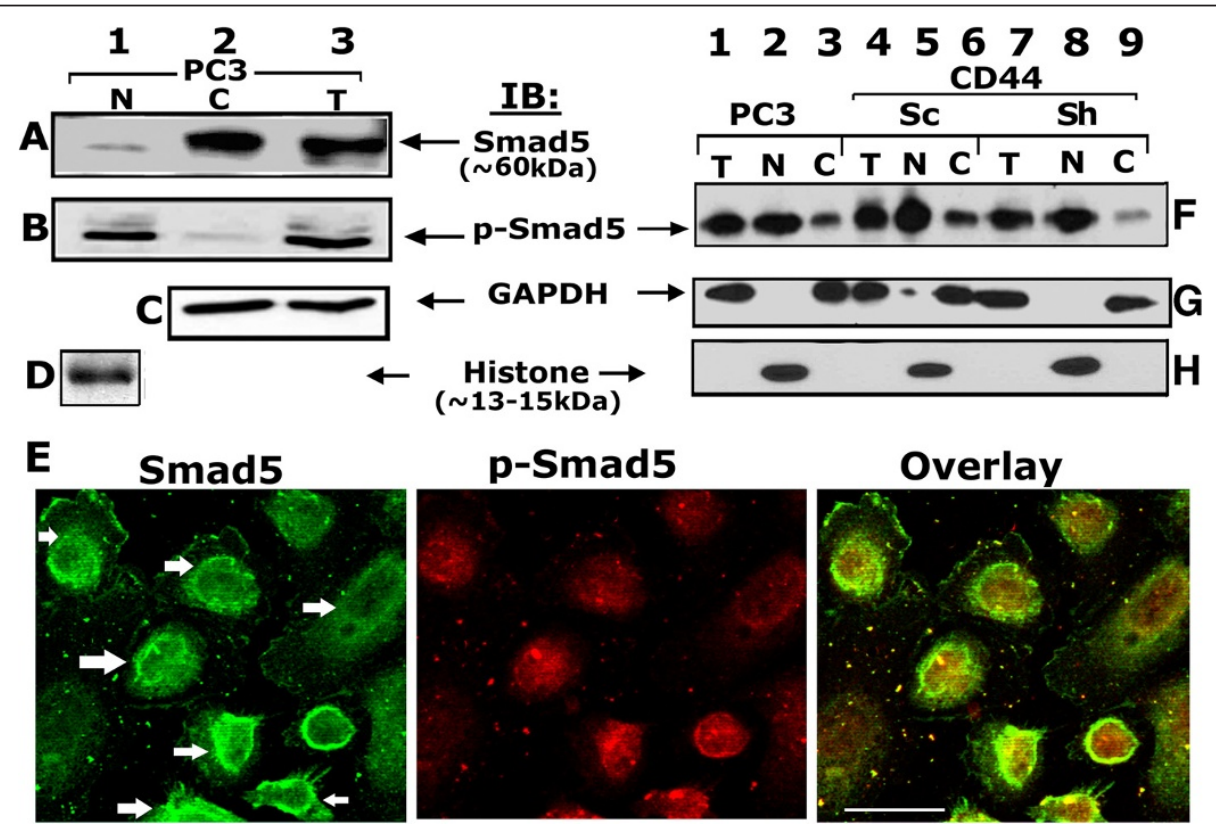

Figure 6 Analysis of Smad 5 phosphorylation in PC3 cells. A and B; F-H. Protein and phosphorylation levels of Smad 5 were determined by Western blot analysis in nuclear (N), cytosolic (C) and total cellular (T) proteins isolated from PC3 cells (A and B) and PC3 cells knockdown of CD44 (F-H). $50 \mu \mathrm{g}$ of indicated protein (A-D, F-H) was used for immunoblotting (IB) analyses. The blot in A was stripped and reprobed successively with p-Smad 5, GAPDH and histone antibodies (B-D). Similarly, the blot in F was stripped and reprobed twice simultaneously with GAPDH and histone antibodies ( $\mathrm{G}$ and H). Immunoblotting with an antibody to GAPDH (C and G) and histone (D and H) was used as a control for normalization of cellular and nuclear protein, respectively. E. Confocal analysis of immunostained PC3 cells with Smad 5 (green) and p-Smad 5 (red) antibodies is shown. Distribution of both Smad 5 and p-Smad 5 is shown in the overlay panel. Scale bar-50 $\mu$ m. The results shown are representative of three independent experiments. 
(Figure 6B, lane 3) may represent the one present in the nucleus $(6 \mathrm{~B}$, lane 1$)$.

Immunostaining and confocal microscopy analyses (Figure 6E) corroborated the immunoblotting analysis. Strong Smad 5 staining was observed at the perinuclear region (indicated by arrows in the green panel) with a diffuse distribution in the nuclei. Distribution in the perinuclear region includes the nuclear membrane. Also, Smad 5 was present in the cytoplasm and plasma membrane, but to a lesser extent (Figure 6E; green panel). However, localization of p-Smad 5 was observed largely in the nucleus (Figure 6E, red). Perinuclear distribution of Smad 5 may support the phosphorylation event and immediate export into the nuclei at the time of transcription.

\section{Phosphorylation of Smad 5 occurs independent of CD44 signaling}

To determine the role of CD44 signaling in the phosphorylation of Smad 5, we used the stable PC3/ShCD44 (801) cell line. Phosphorylation of Smad 5 remained the same in total cellular $(\mathrm{T})$ and nuclear $(\mathrm{N})$ protein of PC3 cells untransfected (Figure 6F, lanes 1 and 2) or transfected with scrambled ShRNA (Figure 6F, lanes 4, 5) and ShRNA (lanes 7 and 8) constructs to CD44. Consistently, phosphorylation is significantly lower in the cytosolic protein (lanes 3, 6, and 9) than total cellular (T) and nuclear $(\mathrm{N})$ proteins (Figure 6F). Knockdown of CD44 signaling had no effects on the expression, phosphorylation or nuclear localization of Smad 5 protein (Figure 6F, lanes 7-9). These findings clearly indicate that CD44 signaling appears to have no role in the phosphorylation of Smad 5.

\section{Phosphorylation of Smad 5 regulates nuclear localization of RUNX2}

Cooperation between RUNX2 and Smads appears to be structurally coupled [24] and this seems to be important in eliciting biological signals that regulate the expression of osteoblast specific genes [26]. Therefore, we assessed in PC3 cells whether RUNX2 and Smad 5 were structurally linked. We used total cellular (T; $100 \mu \mathrm{g})$ and nuclear $(\mathrm{N} ; 50 \mu \mathrm{g})$ lysates for immunoprecipitation with a RUNX2 antibody (Figure 7A). Immunoblotting was performed with a p-Smad 5 antibody. We show here co-precipitation

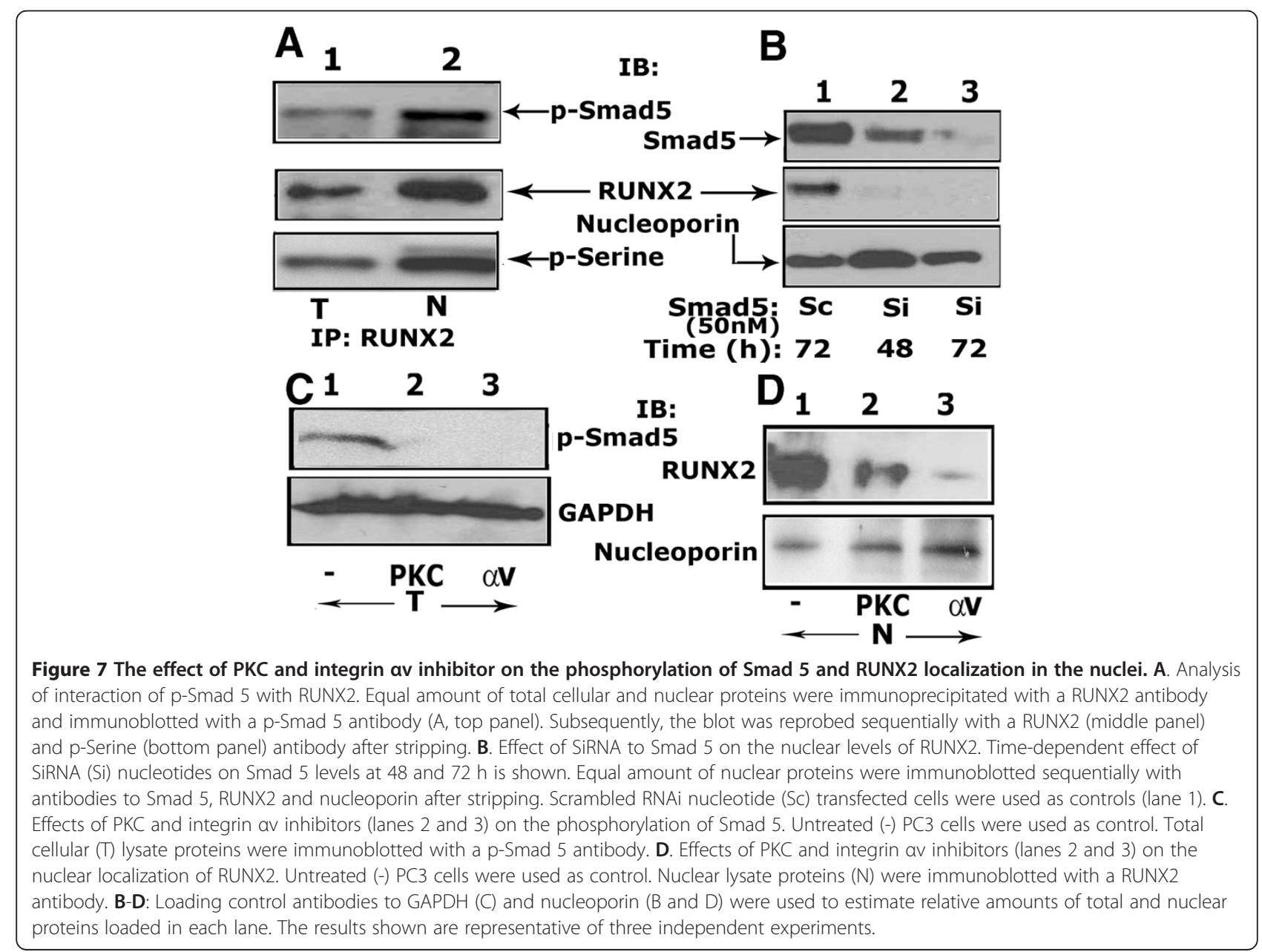


of p-Smad 5 with RUNX2 in total cellular and nuclear lysates (A). However, the levels of immunoprecipitated p-Smad 5 (top panel) and co-immunoprecipitated RUNX2 (bottom panel) were higher in nuclear lysates (A, lane 2). As shown in Figure 5, RUNX2 present in the nucleus is phosphorylated on serine residues (Figure 7A; bottom panel). This suggests that the formation of a RUNX2p-Smad 5 complex takes place in the nucleus and the complex is phosphorylated.

Next we utilized RNA intereference to examine the effects of Smad5 knockdown in the nuclear localization of RUNX2. As shown in Figure 7B, Smad 5 level was reduced in a time-dependent manner at $48 \mathrm{~h}$ and $72 \mathrm{~h}$ (B-top panel, lanes 2 and 3) so did nuclear levels of RUNX2 (middle panel, lanes 2 and 3). These results indicate that RUNX2 nuclear localization of RUNX2 seems to be highly dependent on Smad 5 function.

\section{Alpha $v$ beta 3-PKC dependent pathway regulates the phosphorylation of Smad 5}

In an attempt to delineate the possible signaling pathway involved in the phosphorylation of Smad 5, PC3 cells were treated with a conventional PKC inhibitor (Gö6976; 100nM) and an inhibitor to $\alpha \mathrm{v}$ (cyclic RGD; $100 \mathrm{nM}$ ) for $16 \mathrm{~h}$ at $37^{\circ} \mathrm{C}$ as described previously [52]. Immunoblotting analysis of total cellular lysates ( $\mathrm{T}$, $100 \mu \mathrm{g}$ ) with an antibody to p-Smad 5 was performed. Our data show that these inhibitors blocked the phosphorylation of Smad 5 to a significant level (Figure 7C, lanes 2 and 3). Untreated PC3 cells were used as controls (lane 1). These data provides evidence that $\alpha \mathrm{v} \beta 3$ signaling regulates the phosphorylation of Smad 5, including PKC as an important signaling molecule within the $\alpha v \beta 3$ signaling pathway.

We next asked whether inhibition of Smad 5 phosphorylation reduces the localization of RUNX2 in the nuclei (Figure 7D). We examined RUNX2 levels in the nuclear lysates $(\mathrm{N}, 50 \mu \mathrm{g})$ made from PC3 cells treated with a $\alpha \mathrm{v}$ and PKC inhibitor (lanes 2 and 3). A decrease in the levels of RUNX2 in cells treated with inhibitors (lanes 2 and 3) corresponds with the decrease in the phosphorylation of Smad 5 (Figure 7C, lanes 2 and 3). Following these interesting and novel findings, we suggest that phosphorylation of Smad 5 is an indispensable step for RUNX2 function.

\section{Alpha $v$ beta 3-dependent pathway regulates the expression of RANKL}

We next examined whether inhibition of $\alpha v$ signaling reduces RANKL levels in PC3 cells (Figure 8A) and osteoclast differentiation in vitro (D and $\mathrm{E}$ ). A decrease in the cellular (Figure 8A, lane 1) and secreted (lane 3) levels of RANKL was observed in PC3 cells treated with an inhibitor to $\alpha \mathrm{v}$ (indicated +; Figure 8). Conditioned

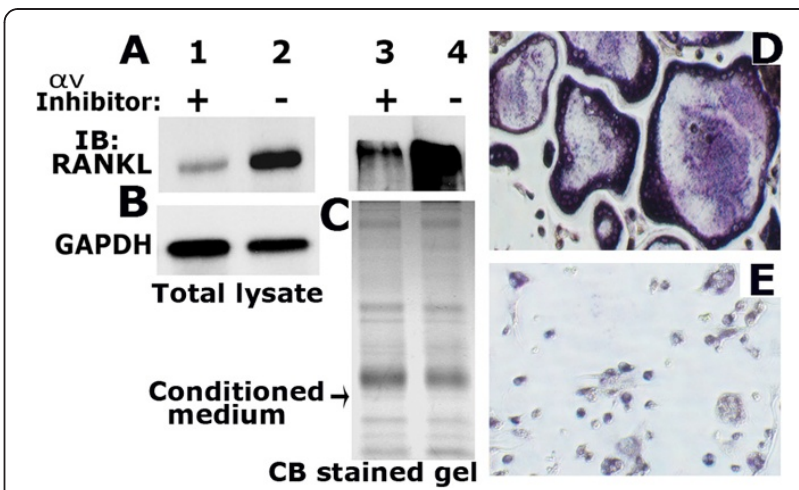

Figure 8 The effect of integrin av inhibitor on RANKL expression and osteoclast differentiation. A-C: Western blot analysis. Equal amount of total cellular lysates $(50 \mu \mathrm{g}$ protein; A, lanes 1 and 2) and conditioned media (CM-20 $\mu$ g protein; lanes 3 and 4) were immunoblotted with a RANKL antibody. CM was used to detect the secreted levels of RANKL. The blot in A was reprobed with a GAPDH antibody after stripping (B). GAPDH level was used as a control for loading. The loading control for the CM is shown by the use of Coomassie blue staining of a gel ran in parallel (C). D and E. The effect of CM on osteoclast differentiation in vitro is shown. TRAP-positive osteoclasts are stained in dark purple. Images were captured (X 200) with an inverted phase contrast microscope. The results shown are representative of three independent experiments.

media from PC3 cells treated with a $\alpha \mathrm{v}$ inhibitor failed to support differentiation of mouse bone marrow cells into multinucleated osteoclasts in vitro (Figure $8 \mathrm{E}$ ). Multinucleated giant osteoclasts were observed in bone marrow cultures treated with $\mathrm{CM}$ media from control PC3 cells (Figure 8D). Taken together, our results indicate that the formation of the nuclear RUNX2/p-Smad 5 complex is a critical mechanism within metastatic prostate cancer cells to facilitate the expression of RANKL.

Phosphorylation of RUNX2 and Smad 5 as well as RANKL expression are significantly increased in human prostate cancer

Immunoblotting analyses of total cellular and membrane protein isolated from human tissues derived from normal prostate (NT) and prostate tumor (TT) were performed with an antibody to RANKL (Figure 9). Expression of RANKL was observed in the total cellular and membrane fractions of the lysate protein from TT (Figure 9A and B, lane 2). RANKL protein was below the level of detection in normal tissue lysates (Figure 9A and B, lane 1).

Next, immunoblotting analyses were performed in the nuclear fractions of NT and TT with antibodies to RUNX2, p-Serine, p-Smad 5 and Smad 5 proteins (Figure 9). While the protein levels remain the same in NT and TT (Figure 9E, lanes 1 and 2), phosphorylation of RUNX2 was markedly increased in the nuclear fraction of TT than NT (Figure 9F, lanes 1 and 2). On the other hand, levels of Smad 5 and p-Smad 5 were elevated 


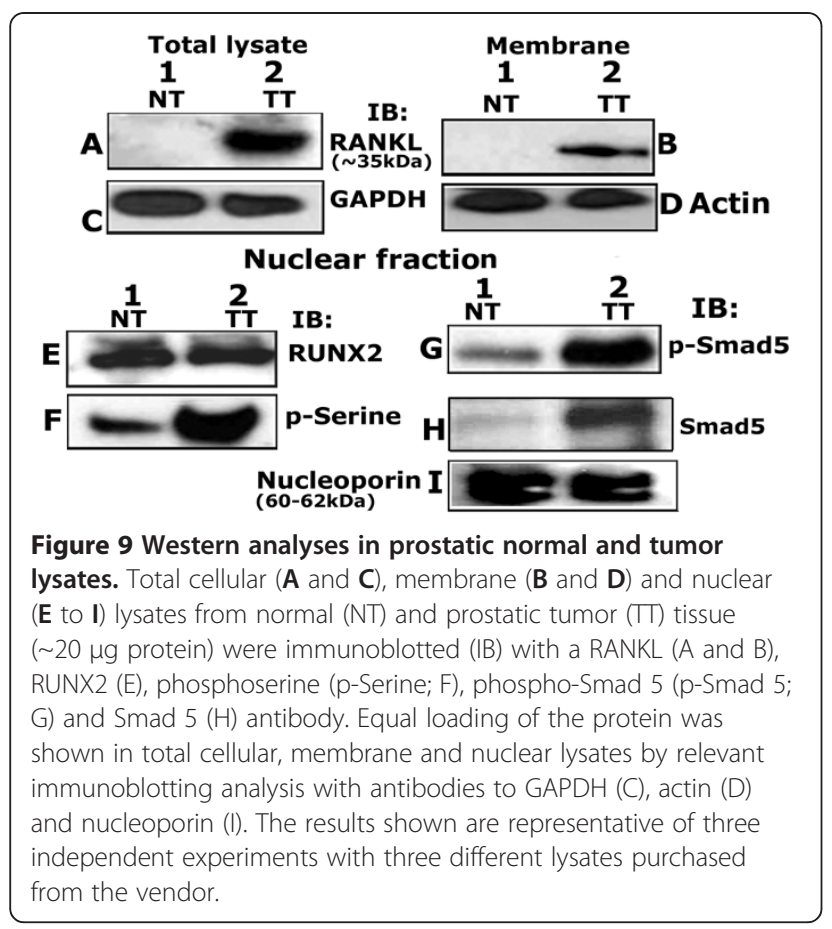

in the nuclear fraction of prostatic TT lysates (Figure 9G and $\mathrm{H}$; lane 2) as compared with NT (G and H, lane 1).

\section{RANKL expression is markedly elevated in human} prostatic adenocarcinoma tissues

To further validate the immunoblotting findings, we carried out immunohistochemistry analyses with antibodies to RANKL, RUNX2, Smad 5 and p-Smad 5 in a human prostate cancer tissue microarray (TMA). The specific tissue microarray used in this study contained 6 cases of prostatic adenocarcinoma with 6 adjacent normal tissues. Relative distribution of indicated proteins in immunostained TMA sections were semi-quantitatively analyzed by two other investigators and provided in Table 1 . Sections shown in A, C, E and G have normal, hyperplastic and mildly dysplastic prostate tissue. Sections in B, D, F and $\mathrm{H}$ contain either moderately or poorly differentiated prostatic adenocarcinoma at grade 2 and 3. Hyperplastic, moderately differentiated prostatic tumor tissue contains luminal or basal epithelial cells. Moderately differentiated prostatic adenocarcinoma cells filling luminal space are indicted by arrows in the sections containing normal and hyperplastic prostate tissue (Figure 10, sections A' and $\left.C^{\prime}\right)$. High magnification regions shown below each of the cores is indicated by a corresponding rectangular field in top panels (A-H). Immunohistochemistry analyses (Figure 10) confirmed the observations shown in Figure 9 in the following aspects: a) RANKL expression increases in prostate cancer tissue (Figure 10B) as compared with normal tissue (Figure 10A). RANKL expression is higher in prostatic cancer tissue (indicated by an arrow in $\mathrm{A}^{\prime}$ ) adjacent to normal tissue (indicated by an asterisk in $\left.A^{\prime}\right)$; b) Diffuse cytoplasmic and intense nuclear distribution of RUNX2 was observed in both normal and prostate cancer tissue sections $\left(\mathrm{C}, \mathrm{D}, \mathrm{C}^{\prime}\right.$ and D'). The unavailability of the phospho-RUNX2 antibody prevented us from determining its localization in the normal and tumor prostatic tissue. However, based on immunoblotting analyses in PC3 nuclear lysates and human prostate cancer cells, we propose that RUNX2 localized in the nucleus of cancer tissue is mostly phosphorylated (Figure 7F, lane 2); c) Diffuse distribution of Smad-5 was observed in normal and prostate carcinoma sections. Distribution of Smad 5 is elevated in carcinoma tissues (F) as compared with normal tissue sections (E). Smad 5 staining was mostly cytoplasmic (E, F, E' and F'). Phospho-Smad 5 (p-Smad 5) staining is very sparse in normal prostatic epithelial cells ( $G$ and $G$ ') but predominates in sections containing adenocarcinoma

Table 1 Expression of RANKL, RUNX2, Smad 5 and p-Smad 5 in prostatic carcinoma and normal tissue microarray sections

\begin{tabular}{|c|c|c|c|c|c|}
\hline Grade & Cells & RUNX2 & Smad 5 & $\mathrm{p}-\mathrm{Smad} 5$ & RANKL \\
\hline \multirow{3}{*}{$\begin{array}{l}\text { Normal prostatic epithelial } \\
\text { cells and PCa adjacent to } \\
\text { these cells }(n=26)\end{array}$} & \multirow{3}{*}{$\begin{array}{l}\text { Cancer cells } \\
\text { appear normal }\end{array}$} & Normal cells $=63.0 \pm 8 \%$ & Normal cells $=18.3 \pm 6 \%$ & Normal cells $=<6 \%$ & Normal cells $=22 \pm 6.5 \%$ \\
\hline & & $P C a=28 \%$ & PCa $=33 \%$ & $P C a=16 \pm 6 \%$ & PCa $=12 \pm 3.1 \%$ \\
\hline & & Stromal cells <5\% & Stromal cells 8-10\% & & Stromal cells $=<6 \%$ \\
\hline \multirow{2}{*}{$\begin{array}{l}\text { Adenocarcinoma Grade } 1 \\
(n=8) \text { (Type: Malignant) }\end{array}$} & \multirow{2}{*}{$\begin{array}{l}\text { Cells appear } \\
\text { normal and well } \\
\text { differentiated }\end{array}$} & $P C a=60.7 \pm 23 \%$ & $P C a=56.4 \pm 8 \%^{* *}$ & $P C a=32 \pm 5 \% * *$ & $\mathrm{PCa}=42 \pm 8.4 \%^{* *}$ \\
\hline & & Stromal cells $=<5 \%$ & Stromal cells =8\% & Stromal cells $=<5 \%$ & Stromal cells $=12 \pm 2.82 \%$ \\
\hline \multirow{2}{*}{$\begin{array}{l}\text { Grade } 2(n=12) \\
\text { (Type: Malignant) }\end{array}$} & \multirow{2}{*}{$\begin{array}{l}\text { Cells appear } \\
\text { slightly different } \\
\text { than normal }\end{array}$} & $P C a=71.3 \pm 20 \%$ & $P C a>63.3 \pm 12 \% \%^{* *}$ & PCa $>59 \pm 14 \% * *$ & PCa $>46 \pm 6.2 \% * *$ \\
\hline & & Stromal cells 5-8\% & Stromal cells 5\% & Stromal cells 5\% & Stromal cells $=10 \pm 3.2 \%$ \\
\hline $\begin{array}{l}\text { Adenocarcinoma } \\
\text { Grade } 2-3 \text { and } 3(n=16) \\
\text { (Type:Malignant) }\end{array}$ & $\begin{array}{l}\text { Cells appear } \\
\text { abnormal Stroma } \\
\text { is less. }\end{array}$ & $P C a=76 \pm 8 \%$ & PCa $>72 \pm 11 \%^{* *}$ & PCa $>78 \pm 18 \%^{* * *}$ & $P C a=65 \pm 13 \% \%^{* *}$ \\
\hline
\end{tabular}

Prostatic carcinoma and normal tissue microarray containing 12 cases/24 cores was used. Stainings were repeated two times. Immunohistochemistry was performed with antibody to RANKL, RUNX2, Smad 5 and phospho-Smad 5 (p-Smad5). ${ }^{* *} p<0.01$ and ${ }^{* * *} p<0.001$ staining intensity vs. normal cells. 

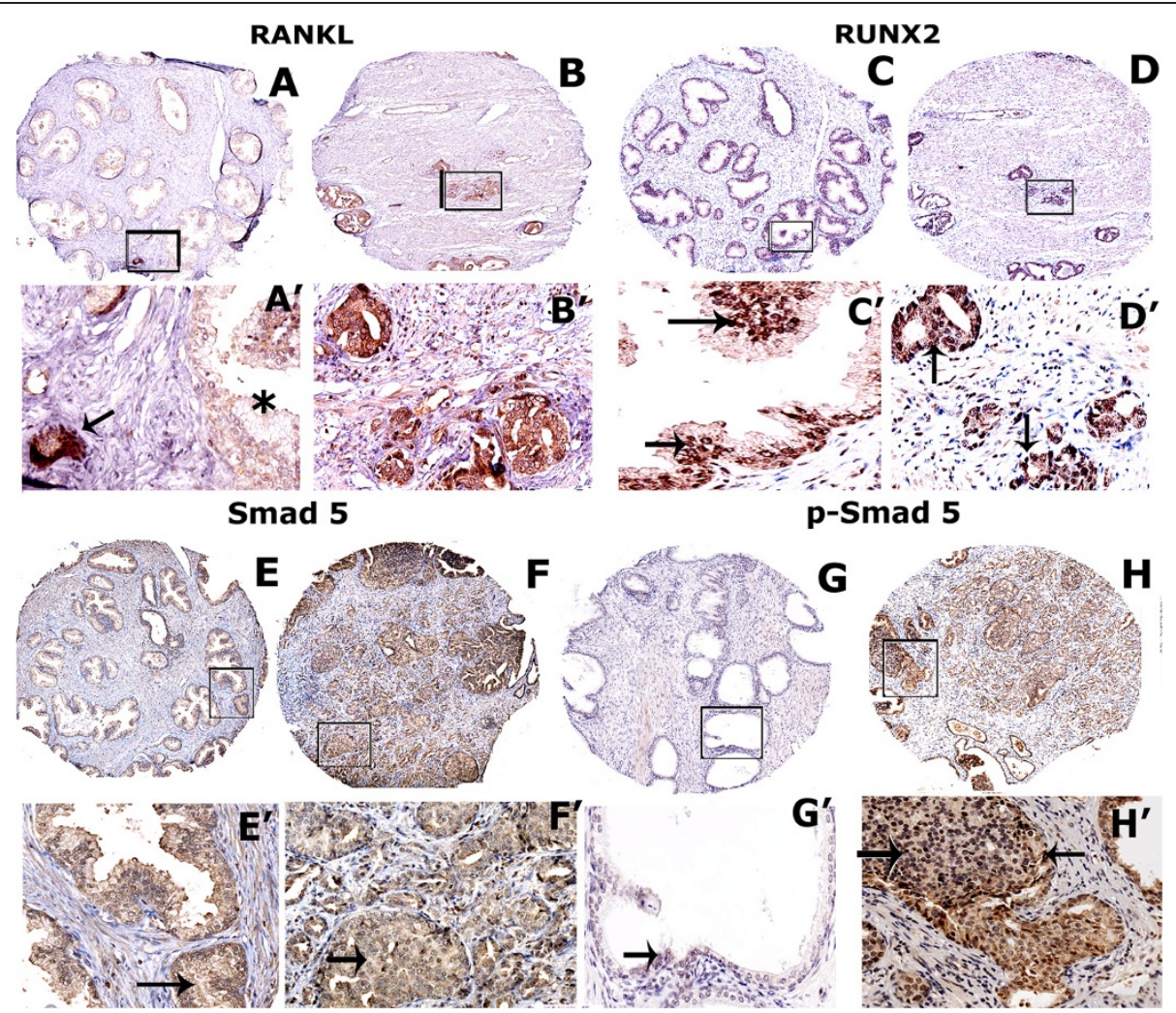

Figure 10 Immunohistochemistry on TMA derived from normal and cancerous prostate tissue. Immunohistochemical staining was performed in prostate cancer and normal tissue microarray with an antibody to RANKL (A and B), RUNX2 (C and D), Smad 5 (E and F) and pSmad $5(\mathbf{G}-\mathbf{H})$. Normal tissue adjacent to prostate cancer are shown in A, C, E and G. Prostate carcinoma at grade 2-3 are shown in B, D, F and H. Arrows in $\mathbf{C}^{\prime}, \mathbf{D}^{\prime} \mathbf{G}^{\prime}$ and $\mathbf{H}^{\prime}$ point to nuclear localization of RUNX2 and p-Smad-5 proteins. An arrow in $A^{\prime}$ points to a prostate carcinoma filled lumen $\left(\mathbf{A}^{\prime}\right)$ adjacent to normal tissue (indicated by an asterisk; $A^{\prime}$ ). Sections were immunostained (brown) with indicated primary antibody as described in the Methods section. Immunostained sections were counterstained with hematoxylin stain (blue). Magnification is 50X in A-H. Location of the high magnification (X200) regions shown in $\mathrm{A}^{\prime}-\mathrm{H}^{\prime}$ is indicated by a rectangle field in A-H. Staining was repeated two times.

cells $\left(\mathrm{H}\right.$ and $\left.\mathrm{H}^{\prime}\right)$. Localization of p-Smad 5 was observed in the nuclei (indicated by arrows in $\mathrm{G}^{\prime}$ and $\mathrm{H}^{\prime}$ ).

\section{Discussion}

Expression of CD44 (standard or variant isoforms) has been considered a prognostic marker for the progression of prostate cancer. The mechanism by which $\mathrm{CD} 44$ regulates the progression of prostate cancer is largely unknown. The present study was performed to evaluate the role of CD44 in prostate cancer-induced bone metastasis. We screened three cell lines (PC3, DU145, and $\mathrm{LNCaP}$ ) for the expression of CD44. Normal prostatic epithelial (HPR-1) and benign prostatic hyperplasic cells (BPH) were used as controls. PC3 and DU145 cells were established from the bone and brain metastatic lesions of a prostate cancer patient, respectively. Our studies are in agreement with the majority of earlier studies [53,54] in the expression of CD44 in androgen independent PC3 and DU145 cells, but not in androgen dependent LNCaP cells, which is established from a lymph node metastasis. Stable expression of androgen receptor in PC3 cells reduces CD44 expression to a significant level (data not shown).

The present study was undertaken to determine the possible mechanisms involved in the formation of osteolytic lesions associated with metastasis of prostate cancer cells to bone and the significance of CD44 and $\alpha \mathrm{v} \beta 3$ signaling. Previous studies in CD44 knockout mice link CD44 receptor with RANKL expression [47]. Our results in PC3 cells show that RANKL expression is in part mediated by CD44 signaling through RUNX2. As a result of CD44 expression, we have found expression of RANKL and MMP9 through RUNX2-dependent signaling in PC3 cells. RUNX2 SiRNA reduces MMP9 expression but not MMP2 at mRNA level. On the other hand, androgen-dependent LNCaP cells demonstrated expression and secretion of MMP2 as a major metalloproteases (Additional file 1: Figure S1). MMP2 expression may occur independent of RUNX2 and CD44 signaling in LNCaP cells. Consistent with our studies, others have shown negligible Runx2 in normal prostate epithelial and non-metastatic LNCaP cells. High Runx2 levels are 
associated with development of large tumors, increased expression of metastasis-related genes (MMP9, MMP13, VEGF, osteopontin) and secreted bone-resorbing factors (PTHrP, IL8) promoting osteolytic disease. Moreover, it was identified in co-culture studies that PC3 cells promote osteoclastogenesis and RUNX2 has a role in it [18]. This suggests a role for RUNX2 in the expression of RANKL.

RUNX proteins are expressed in prostate tissue and prostate cancer cells $[18,55,56]$. Breast and prostate cancers over expressing RUNX2 metastasized predominantly to bone $[16,20]$. We have shown a direct relationship of CD44 expression with RUNX2 activation in androgenindependent PC3 cells. Knockdown of CD44 reduced the expression of RUNX2 at mRNA and protein levels and hence reduced RUNX2-mediated signaling. Our studies demonstrate the possible role of CD44 signaling in RUNX2-mediated expression of RANKL. One possible explanation for RUNX2-regulated RANKL expression in PC3 cells may be associated with the lack of androgen receptor signaling. Androgen receptor was shown to bind RUNX2 and abrogates its binding to DNA and possibly to other nuclear DNAs [14]. It appears that CD44 expression in androgen-independent cells (e.g. PC3 cells) counteracts androgen receptor effects in terms of activation of RUNX2- mediated events. Therefore, knockdown of CD44 signaling in PC3 cells has the potential to reduce RUNX2 mediated signaling.

Hyaluronan (HA), the major non-protein glycosaminoglycan component of the extracellular matrix in mammalian bone marrow, functions in part through its receptor, CD44, to stimulate a series of intracellular signaling events that lead to RANKL expression [47]. We have shown previously that osteopontin (OPN) is secreted by PC3 cells. Over-expression of OPN in PC3 cells increases the secretion of RANKL through $\alpha v \beta 3$ signaling [28]. Our current mechanistic evaluation studies in PC3 cells suggest a role for CD44 signaling in the phosphorylation of a RUNX2 and integrin $\alpha v \beta 3$ signaling in the phosphorylation of Smad-5 independent of CD44 signaling. However, further studies are required to understand the precise contribution of downstream kinase(s) to the regulation of RUNX2 phosphorylation.

Runx2 nuclear localization was found to be upregulated in prostate cancer and was suggested that this could be used as a predictor of metastasis in prostate cancer [57]. Several studies have shown that RUNX2 regulates localization of activated Smads in the subnuclear loci $[24,58,59]$. RUNX2 cooperates with Smads to induce differentiation of osteoblasts $[26,60]$ and expression of collagenase in breast cancer cells [61]. RUNX2 forms complexes with Smad proteins as a requirement for mediating BMP/TGF $\beta$ responsiveness in tumor cells. These effects contribute to tumor growth in bone and the accompanying bone loss in metastatic breast cancer cells [20]. Formation of the Runx2/Smad transcriptional complex is dependent on the phosphorylation state of these proteins [58]. Likewise, we detected predominant localization of phosphorylated RUNX2 and Smad 5 in the nuclei of lysates made from PC3 cells, prostatic adenocarcinoma and in tissue microarray sections containing primary prostatic tumor (grade 2-4).

Distinct relationship has been shown to exist between each Smad and RUNX2, [26,27,58,62,63]. Not only Smad 5 but also Smads 2 and 3 were shown to physically interact with RUNX2 in P19 embryonic carcinoma cells [23]. RUNX2/Smad 3 interaction stimulated collagen 3 expression in breast cancer cells [61]. Runx $2 / \mathrm{Smad} 3$ complex negatively regulated endogenous and TGF-beta-induced connective tissue growth factor gene expression in vascular smooth muscle cells [64]. We have found that PC3 cells express Smad -2, -3 and -5 (Additional file 2: Figure S2). Smad 5 interaction was more with RUNX2 and this interaction regulates the expression of RANKL in prostate cancer cells.

RUNX2/Smad complex was shown to regulate the expression of RANKL in osteoblasts [24]. Although various studies have addressed the role of RUNX2 and Smad(s) in the regulation of expression of RANKL, the mechanisms underlying this process have remained largely unknown. Also the role of Smad5 in the expression of RANKL needs further elucidation. The data presented here show that Smad 5 and RUNX2 are co-immunoprecipitated in the nuclear fraction. RUNX2/Smad 5 complex regulates the expression of RANKL in PC3 cells. Interaction of RUNX2 with RANKL promoter was observed with CHIP assay. Binding of RUNX2 to the ctggaaccactggagt motif site on the RANKL is shown by CHIP assay. Although knockdown of RUNX2 or inhibition of phosphorylation of Smad-5 by an inhibitor to $\alpha v$ reduces the levels of RANKL, direct binding of Smad 5 with RANKL promoter was not observed. Future studies should delineate the relevant interactions between these proteins.

Interestingly, we have also observed reduced levels of RUNX2 and RANKL expression in cells treated with an inhibitor to $\alpha v$ or SiRNA to Smad5. These results indicate that RUNX2 is a major target gene of CD44 and Smad 5 signaling pathway. This is consistence with observations shown by others that Smad 5 is an upstream regulator of RUNX2 [26,51,60]. Over expression of Smad 5 increases RUNX2 levels in human MG63 osteosarcoma cells [51]. RUNX2 expression is transiently up regulated by TGF- $\beta$ and BMP- 2 activated Smads in mesenchymal precursor cell differentiation $[26,60]$. Smad 2 and 3 are expressed in PC3 cells; however, these proteins could not compensate the function of Smad 5 . Therefore, it is possible that, a) Smad 5 which induces RUNX2 expression might also be translocated to 
subnuclear loci by RUNX2; b) Smad 2 or 3 interaction with RUNX2 may not occur for RANKL expression in response to integrin $\alpha v \beta 3$ signaling. BMP2 signaling contributes to the high level of Runx2-Smad interaction which activates RANKL in osteoblasts. CD44/Smad signaling pathway has been shown to have a regulatory role in osteoblast differentiation in the absence of BMPs [65]. The underlying molecular mechanism by which $\alpha v \beta 3$ activated Smad 5 regulates RUNX2 expression needs further elucidation. Taken together, bone metastatic prostate cancer cells (PC3) are osteomimetic and are expressing genes and proteins as observed in osteoblasts. However, the expression of osteoblastic specific genes in metastatic cancer cells does not necessarily involve the same pathway as observed in osteoblasts.

\section{Conclusions}

Runx2 regulates early metastatic events in breast and prostate cancers, tumor growth, and osteolytic bone disease. Runx2 forms co-regulatory complexes with Smads in subnuclear domains to regulate gene transcription. Consideration is given to the potential for inhibition of this transcription factor as a therapeutic strategy upstream of the regulatory events contributing to the complexity of metastasis to bone. BMP/TGF- $\beta$ and other growth factor signaling pathways regulate the formation of RUNX2/Smad complexes which in turn contribute to tumor growth in bone and the accompanying osteolytic disease (rev in [20]. As reported by others [58], we have also shown that RUNX2 and Smad 5 form a complex in the nuclei of PC3 cells and that both Smad5 and RUNX2 in nuclei are phosphorylated to form a transcriptional complex. Indeed, signaling by integrin $\alpha v \beta 3$ and CD44 plays a role in the phosphorylation of Smad 5 and RUNX2, respectively. We have presented evidence that integration of two different signaling pathways (CD44 and $\alpha v \beta 3$ ) facilitate osteoclastogenesis and bone loss via a RUNX2/Smad5/RANKL axis in metastatic prostate cancer cells. Crosstalk between integrin $\alpha v \beta 3$ and CD44 signaling pathway assists in the phosphorylation of Smad 5 and RUNX2, respectively. Further study will be required for comprehensive understanding of the downstream signaling molecules involved in the phosphorylation of RUNX2 and Smad 5 and the details of sequence specific interaction between these proteins.

\section{Materials and methods Materials}

Antibodies to RANKL, RUNX2, Histone and GAPDH as well as HRP-conjugated secondary antibodies (rabbit, goat and mice) were purchased from Santa Cruz Biotechnology, Inc. (Santa Cruz, CA). Antibodies to CD44 and sampler kit containing antibodies to Smads (phospho (P) -Smad1/5, P-Smad2, Smad2, Smad4, Smad 5 and
Smad6) were purchased from Cell Signaling Technologies (Danvers, MA). Macrophage colony-stimulating factor-1 (MCSF-1) was purchased from R\&D Systems (Minneapolis, MN). Cy2- and Cy3-conjugated secondary antibodies were purchased from Jackson Immunoresearch Laboratory, Inc. (West Grove, PA). An inhibitor to PKC (Gö6976) was purchased from Calbiochem (La Jolla, CA). A $\alpha v$ inhibitor (Cyclic RGD peptide) was purchased from Peptides International (Louisville, Kentucky). Complete mini protease inhibitor tablet was purchased from Roche Applied Science (Indianapolis, IN). Protein estimation reagent kit, molecular weight standards for proteins, and polyacrylamide solutions were purchased from Bio-Rad (Hercules, CA). Polyvinyldifluoride (PVDF) membrane for immunoblotting analysis and Amicon centrifugal concentrator devices for concentrating the protein in the conditioned media were obtained from Millipore Corp. (Bedford, MA). ECL reagent was purchased from Pierce (Rockford, IL). Vector Stain Elite and avidin-biotin complex $(\mathrm{ABC})$ kit for immunohistochemistry were bought from Vector Laboratories (Burlingame, CA). Human prostate tumor and normal tissue lysates (total tissue, membrane and nuclear lysates) were purchased from Abcam (Cambridge, MA). TMAs containing 12 (24 cores) 24 (48 cores) and 40 (96 cores) cases were bought from US Biomax, Inc.

\section{Generation of PC3 cells knockdown of CD44}

Four different silencing and one control scramble ShRNA constructs for the CD44 cDNA sequences (Genbank -NM_000610.3) were made using Shanghai Gene Pharm Corporation services (Shanghai, China). Target sequences for each of the silencing and scrambled ShRNA constructs are as follows:

1) 5'GCGCAGATCGATTTGAATATA-3' (shCD44-492)

2) 5'GCTCCACCTGAAGAAG ATTGT-3' (shCD44801)

3) 5'-GCTTC ACCTACTGCAAATCC-3' (shCD441874)

4) 5'-GGA AGAAGATAAAGACCATCC-3' (shCD441994)

5) Scrambled ShRNA $5^{\prime}$ GCATGTAGCGTTCGTAAATAA-3/ (shCD44scramble). Constructs were generated in pGPU6/ GFP/Neo-vector. PC3 cells were transfected with these constructs and vector DNA using lipofectamine 2000 according to the manufacturer's instructions (Invitrogen, Carlsbad, CA). Cells were cultured in Roswell Park Memorial Institute-1640 (RPMI 1640) media containing 10\% FBS. After $24 \mathrm{~h}$ transfection, the cells were selected using G418 sulfate in the same medium. G418 sulfate resistant cells were analyzed for CD44 levels by 
immunoblotting with an antibody to CD44. The constructs which gave the best silencing effect of CD44 in PC3 cells were used for the isolation of individual clones. A significant decrease in the levels of CD44 was observed with shCD44-492 and -801 constructs. Individual clones (about 15-25) were isolated for each construct and cultured in complete medium containing G418 sulfate $(200 \mu \mathrm{g} / \mathrm{ml})$. About two to three clones from each construct (492 and 801) demonstrated a considerable decrease in the levels of CD44. Individual clones from each construct that exhibited highest levels of reduction in endogenous CD44 levels were used for the experiments described here. These cells were designated as $\mathrm{PC} 3 / \mathrm{Si}(\mathrm{CD} 44)$.

\section{Cell culture}

Prostate cancer cells (PC3, PC3 derived cell lines, LNCaP and DU145) and benign prostatic hyperplasic cells (BPH-1) were cultured in RPMI 1640 medium containing $5 \%$ or $10 \%$ fetal bovine serum (FBS) $[28,66]$. HPR1 cells were cultured in keratinocyte medium supplemented with epidermal growth factor (EGF) $(2.5 \mathrm{mg} / 500 \mathrm{ml})$ and bovine pituitary extracts $(25 \mathrm{mg} / 500 \mathrm{ml}$ ) (Gibco BRL, Life Technologies, Bethesda, MD) as described previously [67]. Media were supplemented with penicillin and streptomycin $(1 \%)$ and the cells were maintained at $37^{\circ} \mathrm{C}$ in a humidified incubator with $5 \% \mathrm{CO}_{2}$.

\section{Quantification of RANKL in the conditioned medium}

Cells of interest were grown to $80-90 \%$ confluence in RPMI-1640 medium containing 10\% FBS. Cultures were then switched to serum-free RPMI-1640 medium for $72 \mathrm{~h}$. The harvested CM was concentrated with Amicon centrifugal filter devices (Millipore Corporation, Bedford, MA). Protein concentrations were measured using the Bio-Rad protein assay reagent kit. Quantification of the secreted RANKL in the conditioned media was done by comparative analysis with different concentrations of either BSA or purified GST-RANKL using $12 \%$ polyacrylamide gel containing SDS (SDS-PAGE). Coomassie staining of the SDS-PAGE and immunoblotting with a RANKL antibody were performed to determine the concentration of RANKL in the medium [28].

\section{Preparation of osteoclast precursors}

Mouse osteoclasts were generated in vitro using mouse bone marrow cells as described previously [68]. Cells isolated from five mice were cultured into $100-\mathrm{mm}$ dishes with $20 \mathrm{ml}$ of $\alpha$-MEM medium supplemented with $10 \%$ fetal bovine serum $(\alpha-10)$. After culturing for $24 \mathrm{~h}$, nonadhered cells were layered on histopaque-1077 (Sigma) and centrifuged at $300 \times \mathrm{g}$ for $15 \mathrm{~min}$ at room temperature. The cell layer between the histopaque and the media was removed and washed with $\alpha-10$ medium at $2000 \mathrm{rpm}$ for $7 \mathrm{~min}$ at room temperature. Cells were resuspended in $\alpha$ 10 media and cultured with the appropriate concentrations of M-CSF-1 (10 ng/ml) and RANKL (55-75 ng/ml). In order to determine the effect of secreted RANKL on osteoclast differentiation, mouse bone marrow cells were treated in the same way with M-CSF-1 but with conditioned medium (CM; 50-100 $\mu$ g protein). CM collected from PC3, PC3-derived cell lines, DU145, LNCaP, BPH, and HPR-1 were used for osteoclast differentiation. After 3 days in culture, cultures were added with fresh $\alpha-10$ medium containing M-CSF1 and respective CM. Multinucleated osteoclasts were observed from day 4 onwards. About 75$80 \%$ TRAP-positive multinucleated giant osteoclasts were observed from day 5 onwards [69].

\section{Treatment of PC3 cells with SiRNA to Smad 5 and inhibitors and preparation of total cellular lysates} PC3 cells cultured in RPMI-1640 media containing 10\% FBS at $37^{\circ} \mathrm{C}$ were treated with PKC inhibitor (Go6976; $100 \mathrm{nM}$ ) or integrin $\alpha \mathrm{v}$ inhibitor (cyclic RGD; 100nM) for $16 \mathrm{~h}$. SiRNA and non-targeting SiRNA control nucleotides for Smad 5 were purchased from Santa Cruz biotechnology, Inc. (Catalog No. sc-38378). Transfection was performed with lipofectamine as described previously [70]. Scrambled and SiRNA nucleotides were used to a final concentration of $50 \mathrm{nM}$ for 48 and $72 \mathrm{~h}$. Following various treatments, cells were washed three times with cold PBS and added with cold RIPA lysis buffer (10 mM Tris- $\mathrm{HCl}, \mathrm{pH} 7.2,150 \mathrm{mM} \mathrm{NaCl}, 1 \%$ deoxycholate, $1 \%$ Triton $\mathrm{X}-100$, and $0.1 \%$ SDS) [71]. Lysis buffer was supplemented with EDTA- free complete mini protease inhibitor cocktail (1 tablet per $10 \mathrm{ml}$ lysis buffer) immediately before use. After incubating on ice for $10 \mathrm{~min}$, lysates were centrifuged for $5 \mathrm{~min}$ at $6,000 \mathrm{rpm}$ at $4^{\circ} \mathrm{C}$. The supernatants were saved and protein concentrations were measured using the Bio-Rad protein assay reagent kit. Protein lysates were subjected to SDSPAGE (8 or $12 \%$ gels) and Western blot analysis as described previously [71].

\section{Preparation of cytoplasmic and nuclear protein fractions}

Cells were lysed in a lysis buffer containing $10 \mathrm{mM}$ Tris $\mathrm{pH}$ 7.9, $1.5 \mathrm{mM} \mathrm{MgCl} 2,10 \mathrm{mM} \mathrm{KCl}, 0.5 \mathrm{mM}$ EGTA and protease inhibitor (1 tablet/10 ml buffer). Lysate was centrifuged at $500 \times \mathrm{g}$ to separate the nuclear pellet from the supernatant. The supernatant was considered as a cytosolic fraction. The nuclear pellet was resuspended by pipetting up and down with a P200 pipette tip in a buffer containing $20 \mathrm{mM}$ Tris $\mathrm{pH}$ 7.5, 25\% glycerol, $1.5 \mathrm{mM} \mathrm{MgCl}_{2}, 400 \mathrm{mM} \mathrm{NaCl}$ and $0.5 \mathrm{mM}$ EGTA. The suspension was centrifuged at $20,000 \times \mathrm{g}$ for $15 \mathrm{~min}$ at $4^{\circ} \mathrm{C}$ and the supernatant was used as nuclear fraction. Equal 
concentration of lysate proteins were used for Western blot analysis [71].

\section{Immunostaining}

PC3 cells were cultured on cover slips in a $30 \mathrm{~mm}$ dish for overnight at $37^{\circ} \mathrm{C}$ prior to staining. Cells were washed three times with PBS and fixed in $4 \%$ paraformaldehyde-PBS for $20 \mathrm{~min}$. After washing three times with PBS, cells were permeablized with $0.1 \%$ Triton XPBS for $15 \mathrm{~min}$. Subsequently, cells were blocked and immunostained with antibodies (1:100 dilution) of interest as described previously [70]. Cells were then washed and counterstained with respective isotype specific IgG conjugated with $\mathrm{CY} 2$ and $\mathrm{CY} 3$ fluorophore for 2-3 h at $4^{0} \mathrm{C}$. The cells were washed and mounted on a slide in a mounting solution (Vector Laboratories, Inc.). The immunostained cells were viewed and photographed on a Bio-Rad confocal laser-scanning microscope. Images were stored in TIF image format and processed by the Adobe Photoshop software program (Adobe Systems, Inc., Mountain View, CA).

\section{RNA extraction and quantitative real-time PCR with RUNX2}

Total RNA from different cell lines was isolated with TRIzol kit protocol with the DNA digest (Invitrogen, Carlsbad, CA). Reverse transcription reaction was performed in a $20 \mu$ l-reaction volume with $1 \mu \mathrm{g}$ of total RNA by following the instructions provided by the manufacturer (Invitrogen, Carlsbad, CA). The cDNA was stored at $-20^{\circ} \mathrm{C}$ until further use. For real time PCR, Runx2 primers (forward-5'CGGCCCTCCCTGAACTCT3'; reverse- 5'TGCCTGCCTGGGGTCTGTA3') were used [55]. Glyceraldehyde-3-phosphate dehydrogenase (GAPDH) (forward-5' TGCA CCACCAACTGCTTAG3' and reverse-5'GATGCAGGGATGATGTTC3') was used for normalization. Each reaction was performed in duplicates or triplicates in $25 \mu \mathrm{l}$ volume in 96-well plates with a SYBR green reaction mix (Applied Biosystems Group) in an $\mathrm{ABI} 7000 \mathrm{HT}$ thermocycler $\left(2 \mathrm{~min}\right.$ at $50^{\circ} \mathrm{C}, 10 \mathrm{~min}$ at $95^{\circ} \mathrm{C}$ and 40 cycles of $15 \mathrm{~s}$ at $94^{\circ} \mathrm{C}$ and $1 \mathrm{~min}$ at $60^{\circ} \mathrm{C}$ ) with $600-900 \mathrm{nM}$ primers as described previously [72]. The expression was calculated relative to that of control cells and normalized for GAPDH measured under the same conditions (Applied Biosystems/Roche, Branchburg, NJ), using the $2-\Delta \Delta \mathrm{CT}$ method [73].

\section{Immunohistochemistry}

Prostatic adenocarcinoma tissue microarray (TMA) sections containing 6 cases of prostate adenocarcinoma with 6 adjacent normal prostate tissues in duplicate cores per case were purchased from the US Biomax, Inc (Rockville, MD). TMA sections were processed, stained, and analyzed essentially as described previously [74].
Antigen retrieval was done using a buffer containing $10 \mathrm{mM}$ Tris base pH 9, $1 \mathrm{mM}$ EDTA and 0.05\% Tween 20 in a microwave for $20 \mathrm{~min}$. After incubation with $3 \%$ hydrogen peroxide in PBS for 30 min., sections were washed with PBS and then blocked either in 2.5\% BSA or horse serum in PBS for $1 \mathrm{~h}$ at RT. Sections were then incubated with the primary antibodies diluted in blocking solution overnight at $4^{\circ} \mathrm{C}$. After washing with PBS, slides were incubated with biotinylated secondary antibodies (1:400 dilutions) for $1 \mathrm{~h}$, followed by the avidinbiotin complex $(\mathrm{ABC})$ method using $\mathrm{ABC}$ kit (Vector Laboratories, Burlingame, CA) for $30 \mathrm{~min}$. Slides were washed and developed in 3,3-diaminobenzidine (DAB) for 2-3 min. Immunostained sections were counterstained with hematoxylin, dehydrated and mounted with Permount (Fisher Scientific). Immunostained sections were scanned using an Aperio Scanscope ${ }^{\circledR}$ CS instrument (Aperio scanscope CS system, Vista, CA). Relative distribution of interested proteins in immunostained TMA sections were semi-quantitatively analyzed by two other investigators as well.

\section{Reverse transcription- polymerase chain reaction (RT-PCR) analysis}

RT-PCR was done as described previously [70]. Total $R N A$ was isolated and $\mathrm{CDNAs}$ were synthesized using $2 \mu \mathrm{g}$ of total RNA. RT-PCR was done with the following primers: RUNX2 (406-bp product) - forward, $5^{\prime}$ ATTTAGGGCGCATTCCTCATC-3' and reverse, 5' TGTAATC TGACTCTGTCCTTGTGGAT-3'. GAPDH level was used for normalization. Samples were electrophoresed on an agarose gel and stained with ethidium bromide.

Chromatin immunoprecipitation assay (ChIP) was performed according to the manufacturer's guidelines (Millipore, Cat\#-17-295) and as described previously [75]. Briefly, PC3 cells were fixed by adding formaldehyde (Sigma, St. Louis, MO) to the medium to a final concentration of 1\%. After 15 min the cells were washed, resuspended in CHIP-lysis buffer (Millipore) and sonicated. Immunoprecipitation was carried out at $4^{0} \mathrm{C}$ overnight using anti-RUNX2 $(2 \mu \mathrm{g}$; rabbit polyclonal antibody) or non-immune rabbit IgG as a control. Immune complexes were washed, eluted and protein-DNA cross linking was reversed according to the manufacturer's protocol. Immunoprecipitated DNA was quantified by RT-PCR using primer pairs (forward-5' CTGCGTCTTCTTTAACCCATCT3'; reverse$5^{\prime}$ CССТСССТСТСТСТCAAT СТCT3') in the RANKL promoter with expected product size $153 \mathrm{bp}$.

\section{Statistical analysis}

All experiments were performed in triplicates and repeated three to four times and values presented as 
mean \pm SEM. A value of $\mathrm{p}<0.05$ was considered significant. Statistical significance was determined by analysis of variance (ANOVA) with the Bonferonni corrections (Instat for IBM; Graph pad software; San Diego, CA).

\section{Additional files}

Additional file 1: Figure S1. Analysis of the effects of SiRNA to RUNX2 on MMP9 and MMP2 RNA and protein levels (A-E) and revelation of major MMPs present in PC3 and LNCaP cells (F). A-D: We determined the effects of RUNX2 knockdown on the expression of MMP9 and MMP2 at mRNA (Figure S1-A) and protein levels (Figure S1D) in PC3 cells. Dosedependent decrease in the levels of RUNX2 expression was observed in PC3 cells treated with SiRNA to RUNX2 at concentrations of 10,20, and 50nM. The decrease was maximal (>90\%) at 50nM RUNX2 SiRNA (A, lane 4). PC3 cells treated with scrambled RNAi (50nM) were used as control ( $A$, lane 1). SiRNA to RUNX2 had very negligible effects on the changes in the levels of mRNA expression of MMP2 in PC3 cells (lane 6). GAPDH was used as internal control (Figure S1-B). A decrease in the expression of MMP9 at mRNA (Figure S1-A, lane 4) parallels with the MMP9 activity ( $90 \mathrm{kDa})$ in the conditioned medium isolated from cultures of PC3 cells treated with RUNX2 SiRNA (Figure S1-E, lane 3). MMP9 activity was determined by zymogram analysis. About $50 \mu \mathrm{g}$ membrane protein was used for the gelatin zymography to determine the activities of MMP9 (S1-E). As shown previously [Ref.28], only the active form of MMP-9 was observed in the conditioned medium (Figure S1-E, lanes 1-3). The activity of a recombinant MMP-9 protein containing pro- and active band was used as an identification marker (lane 4 in S1-E). Furthermore, the decrease in the protein levels of RUNX2 $(\sim 55 \mathrm{kDa})$ in SiRNA to RUNX2 treated cells (Figure S1-C, lane 3 ) corresponds with a decrease in the total cellular protein levels of MMP 9 (Figure S1-D, lane 3) but not MMP 2 $(\sim 72 \mathrm{kDa})$. MMP 2 levels remain the same in control untreated as well as scrambled RNAi and SiRNA to RUNX2 treated cells (Figure S1- D). These results imply that the RUNX2 is not a direct binding factor to induce transcriptional activation of MMP 2.F: Zymogram analysis with normal prostatic epithelial cells (HPR1) was used as a control (lane 4) for prostate cancer cells derived from lymph node (LNCaP, lane 2) and bone (PC3, lane 3) metastases. The activity of a recombinant MMP2 and MMP9 protein containing pro and active bands (indicated by arrows) were used as an identification marker (lane 1). LNCaP cells demonstrated MMP2 as a major metalloproteases where as MMP9 was observed as major MMP although MMP2 was observed at mRNA (Figure 1A) and protein levels (Figure S1-D and F) in PC3 cells. About $75 \mu \mathrm{g}$ total cellular protein was used for zymogram analysis as shown previously [ref. 28]. Method: Gelatin zymography: Conditioned media collected from various PC3 cell lines were concentrated approximately 10 -fold) with a centricon concentrator (Amicon, Beverly, MA). Ten micrograms of concentrated media protein in 10-20 $\mu$ l were mixed with gel loading buffer with no reducing agent (BME or DTT) and incubated at RT for 10-15 min. SDSPAGE containing $0.1 \%$ gelatin was used for electrophoresis. Samples were loaded without heating with sample buffer. After electrophoresis, gels were incubated overnight in a buffer containing $50 \mathrm{mM}$ Tris- $\mathrm{HCl}, \mathrm{pH}$ 7.6, $5 \mathrm{mM} \mathrm{CaCl}_{2}, 1 \mu \mathrm{M} \mathrm{ZnCl}$, and $1 \%$ Triton X-100. Triton was used to remove SDS from the gel. Gels were then stained with Coomassie brilliant blue for 2-3 $\mathrm{h}$ and destained with 7\% acetic acid or water. Gelatinolytic activity was detected as clear bands in the background of blue staining [ref.28].

Additional file 2: Figure S2. Immunoblotting analysis for Smad 2, 3, 5

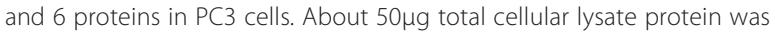
used for immunoblotting with antibodies to phospho-Smad (p-Smad) -2 (60kDa; lane 1), -3 (52 kDa; lane 2), -5 (60kDa; lane 3) and -6 (62kDa; lane 4). Blots were reprobed with an antibody to GAPDH after stripping. Phosphorylation of 2, 3, and 5 was observed in PC3 cells. However, Smad- 5 phosphorylation is significantly more than Smad-2 and 3 (lanes 1 and 2). Phosphorylation of Smad-6 is really negligible or not observed.

\section{Abbreviations}

PKC: Protein kinase C; TMA: Tissue microarray; RANKL: Receptor activator of NFkb ligand; SMID: Smad interacting domain; Chip: Chromatin immunoprecipitation, PCR, Polymerase chain reaction, RT-PCR, Reverse transcriptase PCR, TMA, Tissue microarray; IP: Immunoprecipitation; IB: Immunoblot; CM: Conditioned medium; RUNX2: Runt-related transcription factor 2; SMAD: The gene products of the C. elegans gene Sma and the Drosophila gene 'Mothers Against Decapentaplegic' (Mad). SMAD proteins are signal transducers and transcriptional modulators; $\mathrm{p}-\mathrm{Smad}$ 5: Phosphorylated Smad 5; PKC: Protein Kinase C; Integrin av $\beta 3$ : Vitronectin receptor; CD44: Cluster of Differentiation 44 (also known as cell surface adhesion receptor); SiRNA: Small interfering RNA; ShRNA: Short hairpin RNA; MMP: Matrix metalloproteinase; M-CSF: Macrophage colony stimulating factor.

\section{Competing interests}

The authors declare that they have no competing interests.

\section{Authors' contributions}

AG carried out major experiments including Western blotting with human normal and tumor tissue lysates, immunohistochemistry on TMA, analyses with conditioned medium (Western blotting and osteoclast differentiation), studies with inhibitors (av and PKC) and SiRNA (Smad 5). AG also participated in the MS preparation, statistical analysis of the data, discussion and interpretation of results. WC generated CD44 knockdown stable PC3 cell lines. MAC conceived the study, confocal microscopy analysis of immunostained PC3 cells, RUNX2 knockdown experiments and manuscript preparation. All authors read and approved the final manuscript.

\section{Grant support}

This work was supported by National Institute of Health $(\mathrm{NIH})$ grants AR46292 to MAC and training grant T32 DE007309 to AG. Wei Cao was supported in part by the National Natural Science Foundation of China (grant 30973343) and projects of the Shanghai Science and Technology Committee (grant 10XD1402500).

\section{Acknowledgements}

We thank Dr. C. K. Choo (University of Hong Kong, Hong Kong, China) for HPR-1 cell line [75] and Dr. Pei Feng (School of Dentistry, University of Maryland, Baltimore, MD) for BPH cell line [76]. We thank Dr. Abraham Schneider (School of Dentistry, University of Maryland, Baltimore, MD) for scientific discussion, editorial assistance and technical support in the immunohistochemistry analysis of tissue microarray sections. We gratefully acknowledge the technical assistance of Dr. Cindy Zhou (School of Dentistry, University of Maryland, Baltimore, MD) in scanning the immunostained tissue microarray sections in Aperio Image scope.

\section{Author details}

'Department of Oncology and Diagnostic Sciences, Dental School, University of Maryland, Baltimore, MD 21201, USA. ${ }^{2}$ Department of Oral and Maxillofacial Surgery, Ninth People's hospital, Shanghai Jiao Tong University School of Medicine, Shanghai 200011, China.

Received: 16 February 2012 Accepted: 14 August 2012

Published: 11 September 2012

\section{References}

1. van der Gulden JW, Kiemeney LA, Verbeek AL, Straatman H: Mortality trend from prostate cancer in The Netherlands (1950-1989) 7. Prostate 1994 24:33-38.

2. Brawley OW: Prostate cancer epidemiology in the United States. World J Urol 2012, 30:195-200.

3. Carlin $\mathrm{Bl}$, Andriole $\mathrm{GL}$ : The natural history, skeletal complications, and management of bone metastases in patients with prostate carcinoma 1. Cancer 2000, 88:2989-2994.

4. Sanchez-Sweatman OH, Orr FW, Singh G: Human metastatic prostate PC3 cell lines degrade bone using matrix metalloproteinases. Invasion Metastasis 1998, 18:297-305.

5. Dougall WC: RANKL signaling in bone physiology and cancer. Curr Opin Support Palliat Care 2007, 1:317-322 
6. Hofbauer LC, Schoppet M: Clinical implications of the osteoprotegerin/ RANKL/RANK system for bone and vascular diseases12. JAMA 2004, 292:490-495.

7. Lacey DL, Timms E, Tan H-L, Kelley MJ, Dunstan CR, Burgess T, et al: Osteoprotegerin ligand is a cytokine that regulates osteoclast differentiation and activation. Cell 1998, 93:165-176.

8. Zhang J, Dai J, Qi Y, Lin DL, Smith P, Strayhorn C, et al: Osteoprotegerin inhibits prostate cancer-induced osteoclastogenesis and prevents prostate tumor growth in the bone. J Clin Invest 2001, 107:1235-1244.

9. Zhang J, Dai J, Yao Z, Lu Y, Dougall W, Keller ET: Soluble receptor activator of nuclear factor kappaB Fc diminishes prostate cancer progression in bone. Cancer Res 2003, 63:7883-7890.

10. Miller RE, Roudier M, Jones J, Armstrong A, Canon J, Dougall WC: RANK ligand inhibition plus docetaxel improves survival and reduces tumor burden in a murine model of prostate cancer bone metastasis. Mol Cancer Ther 2008, 7:2160-2169.

11. Yonou H, Ochiai A, Ashimine S, Maeda H, Horiguchi Y, Yoshioka K, et al: The bisphosphonate YM529 inhibits osteoblastic bone tumor proliferation of prostate cancer2. Prostate 2007, 67:999-1009.

12. Schneider A, Kalikin LM, Mattos AC, Keller ET, Allen MJ, Pienta KJ, et al: Bone turnover mediates preferential localization of prostate cancer in the skeleton. Endocrinology 2005, 146:1727-1736.

13. Liao J, McCauley LK: Skeletal metastasis: Established and emerging roles of parathyroid hormone related protein (PTHrP). Cancer Metastasis Rev 2006, 25:559-571.

14. Baniwal SK, Khalid O, Sir D, Buchanan G, Coetzee GA, Frenkel B: Repression of Runx2 by androgen receptor (AR) in osteoblasts and prostate cancer cells: AR binds Runx2 and abrogates its recruitment to DNA. Mol Endocrinol 2009, 23:1203-1214.

15. Barnes GL, Hebert KE, Kamal M, Javed A, Einhorn TA, Lian JB, et al: Fidelity of Runx2 activity in breast cancer cells is required for the generation of metastases-associated osteolytic disease. Cancer Res 2004, 64:4506-4513.

16. Brubaker KD, Vessella RL, Brown LG, Corey E: Prostate cancer expression of runt-domain transcription factor Runx2, a key regulator of osteoblast differentiation and function. Prostate 2003, 56:13-22.

17. Javed A, Barnes GL, Pratap J, Antkowiak T, Gerstenfeld LC, van Wijnen AJ, et al: Impaired intranuclear trafficking of Runx2 (AML3/CBFA1) transcription factors in breast cancer cells inhibits osteolysis in vivo. Proc Natl Acad Sci U S A 2005, 102:1454-1459.

18. Akech J, Wixted JJ, Bedard K, van der Deen M, Hussain S, Guise TA, et al: Runx2 association with progression of prostate cancer in patients: mechanisms mediating bone osteolysis and osteoblastic metastatic lesions. Oncogene 2010, 29:811-821.

19. Selvamurugan N, Shimizu E, Lee M, Liu T, Li H, Partridge NC: Identification and characterization of Runx2 phosphorylation sites involved in matrix metalloproteinase-13 promoter activation. FEBS Lett 2009, 583:1141-1146.

20. Pratap J, Lian JB, Javed A, Barnes GL, van Wijnen AJ, Stein JL, et al: Regulatory roles of Runx2 in metastatic tumor and cancer cell interactions with bone. Cancer Metastasis Rev 2006, 25:589-600.

21. Pratap J, Wixted JJ, Gaur T, Zaidi SK, Dobson J, Gokul KD, et al: Runx2 transcriptional activation of Indian Hedgehog and a downstream bone metastatic pathway in breast cancer cells. Cancer Res 2008, 68:7795-7802.

22. Kitazawa R, Mori K, Yamaguchi A, Kondo T, Kitazawa S: Modulation of mouse RANKL gene expression by Runx2 and vitamin D3. J Cell Biochem 2008, 105:1289-1297.

23. Hanai J, Chen LF, Kanno T, Ohtani-Fujita N, Kim WY, Guo W-H, et al: Interacton and functional cooperation of PEBP2/CBF with Smads. J Biol Chem 1999, 274:31577-31582.

24. Javed A, Afzal F, Bae JS, Gutierrez S, Zaidi K, Pratap J, et al: Specific residues of RUNX2 are obligatory for formation of BMP2-induced RUNX2-SMAD complex to promote osteoblast differentiation. Cells Tissues Organs 2009, 189:133-137.

25. Ito $Y$, Zhang YW: A RUNX2/PEBP2alphaA/CBFA1 mutation in cleidocranial dysplasia revealing the link between the gene and Smad. J Bone Miner Metab 2001, 19:188-194.

26. Lee KS, Kim HJ, Li QL, Chi XZ, Ueta C, Komori T, et al: Runx2 is a common target of transforming growth factor beta1 and bone morphogenetic protein 2, and cooperation between Runx2 and Smad5 induces osteoblast-specific gene expression in the pluripotent mesenchymal precursor cell line C2C12. Mol Cell Biol 2000, 20:8783-8792.
27. Jun JH, Yoon WJ, Seo SB, Woo KM, Kim GS, Ryoo HM, et al: BMP2-activated Erk/MAP kinase stabilizes Runx2 by increasing p300 levels and histone acetyltransferase activity. J Biol Chem 2010, 285:36410-36419.

28. Desai B, Rogers MJ, Chellaiah MA: Mechanisms of osteopontin and CD44 as metastatic principles in prostate cancer cells. Mol Cancer 2007, 6:18.

29. Cooper $\mathrm{CR}$, Chay $\mathrm{CH}$, Pienta KJ: The role of alpha(v)beta(3) in prostate cancer progression. Neoplasia 2002, 4:191-194.

30. Weber GF, Ashkar S: Molecular mechanisms of tumor dissemination in primary and metastatic brain cancers. Brain Res Bull 2000, 53:421-424.

31. Pecheur I, Peyruchaud O, Serre CM, Guglielmi J, Voland C, Bourre F, et al: Integrin alpha(v)beta3 expression confers on tumor cells a greater propensity to metastasize to bone. FASEB J 2002, 16:1266-1268.

32. Boucharaba A, Serre CM, Gres S, Saulnier-Blache JS, Bordet JC, Guglielmi J, et al: Platelet-derived lysophosphatidic acid supports the progression of osteolytic bone metastases in breast cancer. J Clin Invest 2004, 114:1714-1725.

33. Naor D, Sionov RV, Zahalka M, Rochman M, Holzmann B, Ish-Shalom D: Organ-specific requirements for cell adhesion molecules during lymphoma cell dissemination. Curr Top Microbiol Immunol 1998, 231:143-166.

34. Sy MS, Guo YJ, Stamenkovic I: Distinct effects of two CD44 isoforms on tumor growth in vivo. J Exp Med 1991, 174:859-866.

35. Gao AC, Lou W, Dong JT, Isaacs JT: CD44 is a metastasis suppressor gene for prostatic cancer located on human chromosome 11p13. Cancer Res 1997, 57:846-849.

36. Noordzij MA, Van Steenbrugge GJ, Schroder FH, Van Der Kwast TH: Decreased expression of CD44 in metastatic prostate cancer. Int J Cancer 1999, 84:478-483.

37. Tanne Y, Tanimoto K, Tanaka N, Ueki M, Lin YY, Ohkuma S, et al: Expression and activity of Runx2 mediated by hyaluronan during chondrocyte differentiation. Arch Oral Biol 2008, 53:478-487.

38. Hayer S, Steiner G, Gortz B, Reiter E, Tohidast-Akrad M, Amling M, et al: CD44 is a determinant of inflammatory bone loss. J Exp Med 2005, 201:903-914.

39. Cao J, Singleton P, Majumdar S, Burghardt A, Bourguignon GJ, Halloran BP: Hyaluronan increases RANKL expression in mouse primary osteoblasts through CD44. A potential role in age-related bone loss. J Bone Miner Res 2003, 18(S2):S78. Ref Type: Abstract.

40. Ricciardelli C, Russell DL, Ween MP, Mayne K, Suwiwat S, Byers S, et al: Formation of hyaluronan- and versican-rich pericellular matrix by prostate cancer cells promotes cell motility. J Bio/ Chem 2007, 282:10814-10825.

41. Klarmann GJ, Hurt EM, Mathews LA, Zhang X, Duhagon MA, Mistree T, et al: Invasive prostate cancer cells are tumor initiating cells that have a stem cell-like genomic signature. Clin Exp Metastasis 2009, 26:433-446.

42. Hurt EM, Kawasaki BT, Klarmann GJ, Thomas SB, Farrar WL: CD44+ CD24(-) prostate cells are early cancer progenitor/stem cells that provide a model for patients with poor prognosis. Br J Cancer 2008, 98:756-765.

43. Dhir R, Gau JT, Krill D, Bastacky S, Bahnson RR, Cooper DL, et al: CD44 Expression in Benign and Neoplastic Human Prostates. Mol Diagn 1997, 2:197-204.

44. Pratap J, Javed A, Languino LR, van Wijnen AJ, Stein JL, Stein GS, et al: The Runx2 osteogenic transcription factor regulates matrix metalloproteinase 9 in bone metastatic cancer cells and controls cell invasion. Mol Cell Biol 2005, 25:8581-8591.

45. Grier DG, Thompson A, Kwasniewska A, McGonigle GJ, Halliday HL, Lappin TR: The pathophysiology of HOX genes and their role in cancer. J Pathol 2005, 205:154-171.

46. Roccisana JL, Kawanabe N, Kajiya H, Koide M, Roodman GD, Reddy SV: Functional role for heat shock factors in the transcriptional regulation of human RANK ligand gene expression in stromal/osteoblast cells. J Biol Chem 2004, 279:10500-10507.

47. Cao JJ, Singleton PA, Majumdar S, Boudignon B, Burghardt A, Kurimoto P, et al: Hyaluronan increases RANKL expression in bone marrow stromal cells through CD44. J Bone Miner Res 2005, 20:30-40.

48. Tai $S$, Sun Y, Squires JM, Zhang H, Oh WK, Liang CZ, et al: PC3 is a cell line characteristic of prostatic small cell carcinoma. Prostate 2011, 71:1668-1679.

49. Yu C, Yao Z, Dai J, Zhang H, Escara-Wilke J, Zhang X, et al: ALDH activity indicates increased tumorigenic cells, but not cancer stem cells, in prostate cancer cell lines. In Vivo 2011, 25:69-76.

50. Mori K, Kitazawa R, Kondo T, Maeda S, Yamaguchi A, Kitazawa S: Modulation of mouse RANKL gene expression by Runx2 and PKA pathway. J Cell Biochem 2006, 98:1629-1644. 
51. Chang SF, Chang CA, Lee DY, Lee PL, Yeh YM, Yeh CR, et al: Tumor cell cycle arrest induced by shear stress: Roles of integrins and Smad. Proc Natl Acad Sci U S A 2008, 105:3927-3932.

52. Robertson BW, Bonsal L, Chellaiah MA: Regulation of Erk1/2 activation by osteopontin in PC3 human prostate cancer cells. Mol Cancer 2010, 9:260.

53. Yeung F, Law WK, Yeh CH, Westendorf JJ, Zhang Y, Wang R, et al: Regulation of human osteocalcin promoter in hormone-independent human prostate cancer cells. J Biol Chem 2002, 277:2468-2476.

54. Robertson BW, Chellaiah MA: Osteopontin induces beta-catenin signaling through activation of Akt in prostate cancer cells. Exp Cell Res 2010, 316:1-11.

55. van der Deen M, Akech J, Wang T, FitzGerald TJ, Altieri DC, Languino LR, et al: The cancer-related Runx2 protein enhances cell growth and responses to androgen and TGFbeta in prostate cancer cells. J Cell Biochem 2010, 109:828-837.

56. Fowler M, Borazanci E, McGhee L, Pylant SW, Williams BJ, Glass J, et al: RUNX1 (AML-1) and RUNX2 (AML-3) cooperate with prostate-derived Ets factor to activate transcription from the PSA upstream regulatory region. J Cell Biochem 2006, 97:1-17.

57. Chua CW, Chiu YT, Yuen HF, Chan KW, Man K, Wang X, et al: Suppression of androgen-independent prostate cancer cell aggressiveness by FTY720: validating Runx2 as a potential antimetastatic drug screening platform. Clin Cancer Res 2009, 15:4322-4335.

58. Afzal F, Pratap J, Ito K, Ito Y, Stein JL, van Wijnen AJ, et al: Smad function and intranuclear targeting share a Runx2 motif required for osteogenic lineage induction and BMP2 responsive transcription. J Cell Physio/ 2005, 204:63-72.

59. Zaidi SK, Sullivan AJ, van Wijnen AJ, Stein JL, Stein GS, Lian JB: Integration of Runx and Smad regulatory signals at transcriptionally active subnuclear sites. Proc Natl Acad Sci U S A 2002, 99:8048-8053.

60. Lee KS, Hong SH, Bae SC: Both the Smad and p38 MAPK pathways play a crucial role in Runx2 expression following induction by transforming growth factor-beta and bone morphogenetic protein. Oncogene 2002, 21:7156-7163.

61. Selvamurugan N, Kwok S, Partridge NC: Smad3 interacts with JunB and Cbfa1/Runx2 for transforming growth factor-beta1-stimulated collagenase-3 expression in human breast cancer cells. J Biol Chem 2004, 279:27764-27773.

62. Leboy P, Grasso-Knight G, D'Angelo M, Volk SW, Lian JV, Drissi H, et al: Smad-Runx interactions during chondrocyte maturation. J Bone Joint Surg Am 2001, 83-A(Suppl 1):S15-S22.

63. Hjelmeland AB, Schilling SH, Guo X, Quarles D, Wang XF: Loss of Smad3-mediated negative regulation of Runx2 activity leads to an alteration in cell fate determination. Mol Cell Biol 2005, 25:9460-9468.

64. Ohyama Y, Tanaka T, Shimizu T, Matsui H, Sato H, Koitabashi N, et al: Runx2/Smad3 complex negatively regulates TGF-beta-induced connective tissue growth factor gene expression in vascular smooth muscle cells. J Atheroscler Thromb 2012, 19:23-35.

65. Tanikawa R, Tanikawa T, Hirashima M, Yamauchi A, Tanaka Y: Galectin-9 induces osteoblast differentiation through the CD44/Smad signaling pathway. Biochem Biophys Res Commun 2010, 394:317-322.

66. Wang CY, Lee LH: Mutagenicity and antibacterial activity of hydroxamic acids. Antimicrob Agents Chemother 1977, 11:753

67. Choo CK, Ling MT, Chan KW, Tsao SW, Zheng Z, Zhang D, et al: Immortalization of human prostate epithelial cells by HPV 16 E6/E7 open reading frames. Prostate 1999, 40:150-158.

68. Chellaiah M, Kizer N, Silva M, Alvarez U, Kwiatkowski D, Hruska KA: Gelsolin deficiency blocks podosome assembly and produces increased bone mass and strength. J Cell Biol 2000, 148:665-678.

69. Gupta A, Lee BS, Khadeer MA, Tang Z, Chellaiah M, Abu-Amer Y, et al: Leupaxin is a critical adaptor protein in the adhesion zone of the osteoclast. J Bone Miner Res 2003, 18:669-685.

70. Desai B, Ma T, Zhu J, Chellaiah MA: Characterization of the expression of variant and standard CD44 in prostate cancer cells: identification of the possible molecular mechanism of CD44/MMP9 complex formation on the cell surface. J Cell Biochem 2009, 108:272-284.

71. Chellaiah M, Hruska KA: Osteopontin stimulates gelsolin associated phosphoinositide levels and Ptdlns 3-hydroxyl kinase. Mol Biol Cell 1996, 7:743-753.
72. Ma T, Sadashivaiah $K$, Chellaiah MA: Regulation of sealing ring formation by L-plastin and cortactin in osteoclasts. J Biol Chem 2010, 285:29911-29924.

73. Livak KJ, Schmittgen TD: Analysis of relative gene expression data using real-time quantitative PCR and the 2(-Delta Delta $C(T)$ ) Method. Methods 2001, 25:402-408.

74. Schneider A, Younis RH, Gutkind JS: Hypoxia-induced energy stress inhibits the mTOR pathway by activating an AMPK/REDD1 signaling axis in head and neck squamous cell carcinoma. Neoplasia 2008, 10:1295-1302.

75. Singh IS, Gupta A, Nagarsekar A, Cooper Z, Manka C, Hester L, et al: Heat shock co-activates interleukin-8 transcription. Am J Respir Cell Mol Biol 2008, 39:235-242.

76. Feng P, Li TL, Guan ZX, Franklin RB, Costello LC: Direct effect of zinc on mitochondrial apoptogenesis in prostate cells. Prostate 2002, 52:311-318.

doi:10.1186/1476-4598-11-66

Cite this article as: Gupta et al: Integrin av $\beta 3$ and CD44 pathways in metastatic prostate cancer cells support osteoclastogenesis via a Runx2/Smad 5/receptor activator of NF-kB ligand signaling axis. Molecular Cancer 2012 11:66.

\section{Submit your next manuscript to BioMed Central and take full advantage of:}

- Convenient online submission

- Thorough peer review

- No space constraints or color figure charges

- Immediate publication on acceptance

- Inclusion in PubMed, CAS, Scopus and Google Scholar

- Research which is freely available for redistribution

Submit your manuscript at www.biomedcentral.com/submit
C) Biomed Central 